\title{
Structural insights into conformational stability of ESR1 and structure base screening of new potent inhibitor for the treatment of Breast Cancer
}

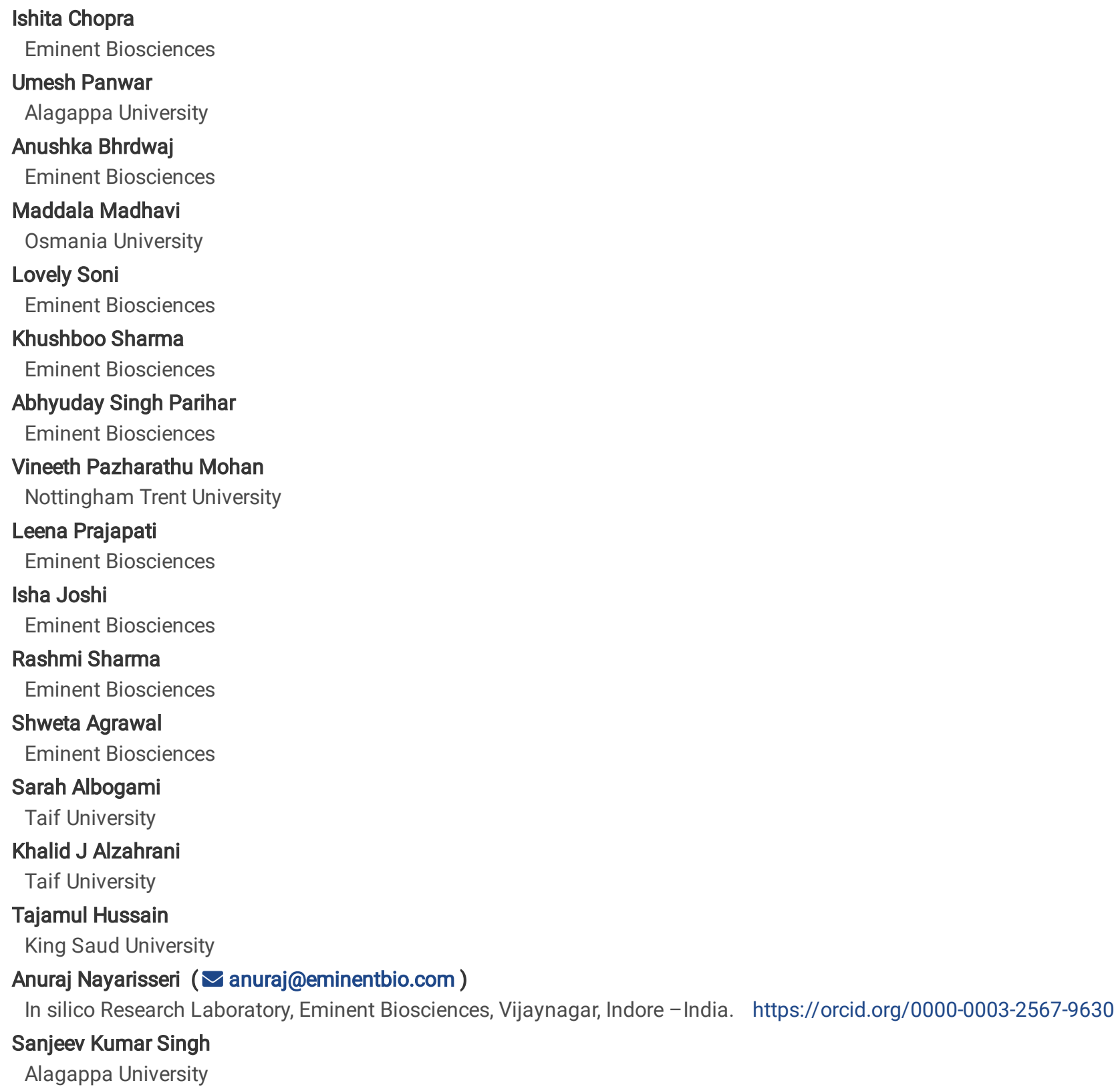

\section{Research Article}

Keywords:

Posted Date: April 6th, 2022

DOI: https://doi.org/10.21203/rs.3.rs-1413803/v2

License: @ (1) This work is licensed under a Creative Commons Attribution 4.0 International License. Read Full License 


\section{Abstract}

Estrogen receptor alpha (ERa), a nuclear receptor protein encoded by the estrogen receptor1 (ESR1) gene, is an important biomarker in breast cancer diagnosis. Any dysregulation in its expression can actively implicate the development and progression of the disease. ERa is abnormally expressed in around $60 \%$ of the active cases, making it an important therapeutic target. In this study, we report the application of computational approaches to identify suitable drug-like molecules, which share similar ligand binding dynamics with ERa. Structure-based virtual screening(SBVS), docking, and inhibitor dynamics are used to study the ligand binding and interaction profiling of the anticipated ligand molecule, at the active site of the 4-hydroxytamoxifen (OHT) protein (PDB Id: 3ERT). SBVS analysis follows HTVS, SP, and XP protocol in comparison to the ZINC and $\mathrm{NCl}$, to retrieve 20bestligandhits as effective inhibitors; All the compounds have shown significant interaction with active site residues (Leu346, Thr347, Asp351, Glu353, Trp383, Leu387, and Arg394) of the 4-hydroxytamoxifen. Moreover, the docking study was used to screen the top 5 compounds: ZINC13377936, NCI35753, ZINC35465238, ZINC14726791, and NCI663569. We also, employed molecular dynamics simulations to explore the binding dynamics present at the atomic level. Our MDS results have revealed the compounds (ZINC13377936 and NCl35753) with outstanding binding stability and lesser fluctuations. Both above hits possess a high potential as future therapeutic agents, acting by the mechanism of competitive inhibition against the ERa protein in breast cancer.

\section{Introduction}

Among all malignant cancers, Breast Cancer is the most common cause of cancer-related deaths in women worldwide and it is a heterogenous disease at the molecular level. Myriad studies have revealed that epigenetic alterations play a prominent role as an early and common mediator for multiple events in cancer. DNA methylation, an epigenetic modification, plays a chief role in deciding the carcinogenic potential, rate of progression, and overall prognosisof various human malignant tumours. The enrichment of DNA methylation at promoter regions of various tumour suppressor genes (p16, ESR1, GSTP1, and PITX) is shown to be associated with the development, and progression of breast cancer. Estrogen receptor-a (ESR1) belongs to the family of nuclear receptor proteins that are involved in the control and regulation of a majority of estrogen-responsive genes(ERG). Any aberrancy in its expression pattern is associated with the active development of breast cancer. The methylation of the ESR1 promoter leads toa poor prognosis in breast cancer [1].

Estrogen binding with the estrogen-receptor (ER) on the nuclear membrane generates a signaling cascade that increases the mitotic potential of the breast epithelium. The allelic polymorphism of the ESR1 gene decides the intensity of associated carcinogenicity developed as a response to the ligand binding. Different SNPs in the gene encoding ERa, in normal and neoplastic breast tissue, have been linked with the different clinical phenotypes[2].

Estrogen binds with the hormone-binding domain of ERa to form an intermediate complex; this, on dimerization associates with other coregulatory proteins to form a final complex which can activate or repress the transcription of ERG. Co-activators (AIB1 or SRC3) assist in the binding of the DNA binding domain of ERa at the estrogen-response-elements located on the promoter of ERG [3]. The estrogen-independent activation of ERais controlled byreceptor tyrosine kinases (RTK). On stimulation by certain signalling molecules like Rg1, RTK induces downstream MEK/ERK signalling cascade which phosphorylates the AF-1 domain of ERa. The phosphorylated ERa regulates gene expression by the principle of protein-protein interaction with a specific group of transcriptional factors. The final regulated product of both of these pathways controls many important cross-talks taking place in the cell cycle, angiogenesis, differentiation, proliferation, apoptosis, and survival [4][Fig. 1].

Augmented estrogen exposures have proved to escalate the risk associated with breast cancer. The underlying insightful mechanisms guiding this risk profile are not entirely characterised. However, immune histochemistry studies have shown that ER over expression increases the estrogen sensitivity and responsiveness of benign breast epithelium tissues [5].Furthermore, a high percentage of the population exhibiting ESR1 amplification can be observed among all primary cases of breast cancer. Therapeutic agents targeting ESR1 in combination with optimised hormonal therapy can be used effectively for the treatment of this populational subtype [6]. The current investigation is aimed to identify high affinity and effective inhibitors towards ERa by structure-based virtual screening and molecular docking studies [7-15]. To explore the variations in the protein-ligand interaction, Molecular Dynamics Simulation (MDS) and Principal Component Analysis (PCA) methods were engaged [16-19]. A full-atom molecular dynamics simulation method was used to investigate the molecular mechanism of the interaction between the inhibitors with ESR1. The conformational changes and dynamical properties were calculated using principal component analysis and free energy landscape methods. The binding free energy was evaluated using MM/MMGBSA [20-28].

\section{Results And Discussion}


The performed study tends to report the appliance of structure-based virtual screening, docking and dynamics for ERa inhibitors, which results in the binding of ligands into the active site of the targeted protein. Based on structural and molecular information, effective compounds were identified leading towards the inhibition of Era which can be potential therapeutic agents in the future.

\subsection{Re-docking and structure-based virtual screening (SBVS) analysis.}

Docking studies provides a great understanding of the drug interaction mechanism with the protein. Thus, the re-docking of co-crystallized inhibitor $(\mathrm{OHT})$ has shown the binding interaction within the same binding site in the targeted receptor with an RMSD value of $0.336 \AA$ as illustrated in Fig. 2. Docking results were analyzed with perfect binding confirmation, higher docking score, glide energy and e-model; tabulated in Table 1.

Table 1

Re-docking of the co-crystallized inhibitor into the active site of the co-crystallized compound within the protein.

\begin{tabular}{|lllll|}
\hline Name of Inhibitors & $\begin{array}{l}\text { Docking } \\
\text { Score } \\
(\mathrm{kcal} / \mathrm{mol})\end{array}$ & $\begin{array}{l}\text { Glide } \\
\text { Energy } \\
(\mathrm{kcal} / \mathrm{mol})\end{array}$ & $\begin{array}{l}\text { No. Hydrogen Bond } \\
\text { present }\end{array}$ & $\begin{array}{l}\text { Interactive residues for Hydrogen } \\
\text { bond }\end{array}$ \\
\hline $\begin{array}{l}\text { Co-crystallized Ligand } \\
(\mathrm{OHT})\end{array}$ & -10.009 & -62.124 & 02 & $\begin{array}{l}\text { Distance } \\
(\AA)\end{array}$ \\
& & & Glu353, & Arg394 \\
\hline
\end{tabular}

Further, the SBVS was applied to identify the exact conformation and orientation of the drug-like molecule into the same binding site of targeted protein using HTVS, SP, and XP protocol with default parameters against the two different chemical libraries (ZINC and NCI), retrieved best 20 hits ligands as effective inhibitors in terms of the favorable condition of pharmacokinetic properties including highest docking score and glide energy are shown in Table 2. All the compounds have shown the significant interaction with active site residues (Leu346, Thr347, Asp351, Glu353, Trp383, Leu387, and Arg394) of the ESR1. 
Table 2

Virtual screening top hits from Zinc and $\mathrm{NCI}$ Databases, respectively.

\begin{tabular}{|c|c|c|c|c|c|c|}
\hline \multicolumn{7}{|c|}{ Zinc Virtual Screening. } \\
\hline \multirow[t]{3}{*}{$\begin{array}{l}\text { S. } \\
\text { No. }\end{array}$} & Compound ID & $\begin{array}{l}\text { Docking } \\
\text { Score }\end{array}$ & $\begin{array}{l}\text { Glide } \\
\text { Energy }\end{array}$ & $\begin{array}{l}\text { No. Hydrogen Bond } \\
\text { present }\end{array}$ & $\begin{array}{l}\text { Interactive residues for } \mathrm{H}- \\
\text { bond }\end{array}$ & $\begin{array}{l}\text { Distance } \\
(\AA)\end{array}$ \\
\hline & & (kcal/ & (kcal/ & & & \\
\hline & & mol) & mol) & & & \\
\hline \multirow[t]{4}{*}{1} & ZINC35465238 & -13.284 & -46.171 & 04 & Thr347 & 2.09 \\
\hline & & & & & Glu353 & 1.77 \\
\hline & & & & & Leu387 & 2.11 \\
\hline & & & & & $\operatorname{Arg} 394$ & 2.09 \\
\hline \multirow[t]{3}{*}{2} & ZINC13377936 & -12.839 & -53.516 & 04 & Thr347 & 2.1 \\
\hline & & & & & Glu353 & $1.63 \& 1.77$ \\
\hline & & & & & $\operatorname{Arg} 394$ & 2.10 \\
\hline \multirow[t]{3}{*}{3} & ZINC14726791 & -12.522 & -44.602 & 04 & Thr347 & 1.68 \\
\hline & & & & & Glu353 & $1.62 \& 1.86$ \\
\hline & & & & & $\operatorname{Arg} 394$ & 2.05 \\
\hline \multirow[t]{3}{*}{4} & ZINC14726789 & -12.475 & -50.847 & 04 & Thr347 & 2.22 \\
\hline & & & & & Glu353 & $1.62 \& 1.86$ \\
\hline & & & & & $\operatorname{Arg} 394$ & 2.09 \\
\hline \multirow[t]{2}{*}{5} & ZINC05359847 & -12.357 & -29.311 & 03 & Glu353 & $1.76 \& 2.74$ \\
\hline & & & & & Gly420 & 2.13 \\
\hline \multirow[t]{3}{*}{6} & ZINC85489116 & -12.267 & -50.077 & 03 & Asp351 & 1.85 \\
\hline & & & & & $\operatorname{Arg} 394$ & 1.67 \\
\hline & & & & & Gly420 & 1.78 \\
\hline \multirow[t]{3}{*}{7} & ZINC03589221 & -12.218 & -51.246 & 04 & Thr347 & 1.96 \\
\hline & & & & & Glu353 & $1.62 \& 1.68$ \\
\hline & & & & & Arg394 & 2.13 \\
\hline \multirow[t]{3}{*}{8} & ZINC85569243 & -12.058 & -44.123 & 04 & Glu353 & $1.62 \& 1.66$ \\
\hline & & & & & $\operatorname{Arg} 394$ & 1.88 \\
\hline & & & & & Gly420 & 2.19 \\
\hline \multirow[t]{3}{*}{9} & ZINC00056472 & -12.014 & -47.512 & 04 & Thr347 & 2.16 \\
\hline & & & & & Glu353 & $1.79 \& 1.68$ \\
\hline & & & & & $\operatorname{Arg} 394$ & 2.12 \\
\hline \multirow[t]{3}{*}{10} & ZINC31169866 & -12.011 & -53.682 & 04 & Thr347 & 1.87 \\
\hline & & & & & Glu353 & $1.63 \& 1.58$ \\
\hline & & & & & Arg394 & 2.16 \\
\hline
\end{tabular}




\begin{tabular}{|c|c|c|c|c|c|c|}
\hline \multicolumn{7}{|c|}{ Zinc Virtual Screening. } \\
\hline \multirow[t]{3}{*}{$\begin{array}{l}\text { S. } \\
\text { No. }\end{array}$} & Compound ID & $\begin{array}{l}\text { Docking } \\
\text { Score }\end{array}$ & $\begin{array}{l}\text { Glide } \\
\text { Energy }\end{array}$ & $\begin{array}{l}\text { No. Hydrogen Bond } \\
\text { present }\end{array}$ & $\begin{array}{l}\text { Interactive residues for } \mathrm{H}- \\
\text { bond }\end{array}$ & $\begin{array}{l}\text { Distance } \\
(\AA)\end{array}$ \\
\hline & & (kcal/ & (kcal/ & & & \\
\hline & & mol) & mol) & & & \\
\hline \multirow[t]{3}{*}{1} & 35753 & -12.872 & -47.536 & 04 & Glu353 & $1.83 \& 1.68$ \\
\hline & & & & & Arg394 & 1.95 \\
\hline & & & & & Gly420 & 1.89 \\
\hline \multirow[t]{4}{*}{2} & 663569 & -12.613 & -44.045 & 04 & Thr347 & 2.05 \\
\hline & & & & & Glu353 & 1.92 \\
\hline & & & & & Leu387 & 1.76 \\
\hline & & & & & Arg394 & 2.16 \\
\hline \multirow[t]{4}{*}{3} & 747974 & -12.55 & -65.238 & 04 & Asp351 & 1.76 \\
\hline & & & & & Glu353 & 1.81 \\
\hline & & & & & $\operatorname{Arg} 394$ & 2.15 \\
\hline & & & & & Gly420 & 2.01 \\
\hline \multirow[t]{4}{*}{4} & 706725 & -12.546 & -64.12 & 04 & Asp351 & 1.71 \\
\hline & & & & & Glu353 & 1.81 \\
\hline & & & & & Arg394 & 2.14 \\
\hline & & & & & Gly420 & 2.00 \\
\hline 5 & 665877 & -12.53 & -47.689 & 01 & Glu353 & 1.49 \\
\hline \multirow[t]{2}{*}{6} & 211751 & -12.475 & -56.377 & 02 & Leu346 & 2.05 \\
\hline & & & & & Glu353 & 1.59 \\
\hline \multirow[t]{4}{*}{7} & 32653 & -12.382 & -47.57 & 04 & Leu346 & 2.03 \\
\hline & & & & & Glu353 & 1.66 \\
\hline & & & & & Arg394 & 2.20 \\
\hline & & & & & Gly420 & 1.85 \\
\hline \multirow[t]{3}{*}{8} & 286612 & -12.076 & -55.227 & 03 & Asp351 & 1.73 \\
\hline & & & & & Glu353 & 1.58 \\
\hline & & & & & $\operatorname{Arg} 394$ & 2.10 \\
\hline \multirow[t]{3}{*}{9} & 153166 & -12.022 & -55.945 & 04 & Asp351 & 1.69 \\
\hline & & & & & Glu353 & $1.66 \& 1.65$ \\
\hline & & & & & Arg394 & 1.90 \\
\hline \multirow[t]{3}{*}{10} & 32081 & -11.761 & -42.951 & 03 & Glu353 & 1.77 \\
\hline & & & & & Leu387 & 2.16 \\
\hline & & & & & Arg394 & 2.00 \\
\hline
\end{tabular}

\subsection{ADME properties}

Inadequate ADME properties of compounds are a major cause of clinical trial failures leading to wastage of resources during later stages of development. Prediction of ADME properties will help to improve compounds under consideration and to identify the lead compounds showing optimal performance during clinical trials. Therefore, these properties were predicted using the Schrodinger QikProp module. We 
evaluated the properties within the standardized range defined for human use such as Molecular weight (MW 130-500), H-bond donor (< 5.0), H-Bond acceptors (< 10.0), the octanol/water partition coefficient $\log (-2$ to 6.2$)$, the aqueous solubility $\log (\mathrm{mol} / \mathrm{L})(-6.5$ to 0.5$)$, Predicted Caco-2 cell permeability in $\mathrm{nm} / \mathrm{s}$ (acceptable range: $<25$ is poor and $>500$ is great), Predicted apparent MDCK cell permeability in $\mathrm{nm} / \mathrm{s}$, CNS activity -2 (inactive) to +2 (active), Lipinski's rule of five and Jorgensen rule of three, Percentage of human oral absorption (=> $80 \%$ is high, $<25 \%$ is low), demonstrated in Table 3 , indicating screened compounds which can be a promising lead in drug discovery development.

Table 3

ADME profile of Screened hits and Reference Compound.

\begin{tabular}{|c|c|c|c|c|c|c|c|c|c|c|c|c|c|}
\hline \multirow[t]{3}{*}{$\begin{array}{l}\text { S. } \\
\text { No. }\end{array}$} & \multirow[t]{3}{*}{ Compound ID } & \multirow[t]{3}{*}{ MW } & \multirow[t]{3}{*}{ HBD } & \multirow[t]{3}{*}{ HBA } & \multirow{2}{*}{$\begin{array}{l}\text { QP } \\
\text { log }\end{array}$} & \multirow{3}{*}{$\begin{array}{l}\text { QP } \\
\text { logs }\end{array}$} & \multirow{3}{*}{$\begin{array}{l}\text { QPP } \\
\text { Caco }\end{array}$} & \multirow{3}{*}{$\begin{array}{l}\text { QPP } \\
\text { MDCK }\end{array}$} & \multirow{3}{*}{$\begin{array}{l}\text { QP } \\
\text { log } \\
\text { BB }\end{array}$} & \multirow{3}{*}{$\begin{array}{l}\text { QP } \\
\text { log } \\
\text { KP }\end{array}$} & \multirow[t]{3}{*}{$\begin{array}{l}\text { Rule } \\
\text { of } 5\end{array}$} & \multirow[t]{3}{*}{$\begin{array}{l}\text { Rule } \\
\text { of } 3\end{array}$} & \multirow[t]{3}{*}{$\% \mathrm{HOA}$} \\
\hline & & & & & & & & & & & & & \\
\hline & & & & & $\mathrm{Po} / \mathrm{w}$ & & & & & & & & \\
\hline 1 & ZINC35465238 & 316.353 & 4 & 4.7 & 1.772 & -3.639 & 120.698 & 50.324 & -1.474 & -4.187 & 0 & 1 & 74.577 \\
\hline 2 & ZINC13377936 & 330.38 & 4 & 5 & 2.284 & -4.018 & 59.399 & 23.386 & -2.647 & -3.861 & 0 & 1 & 72.067 \\
\hline 3 & ZINC14726791 & 300.354 & 4 & 3 & 2.054 & -3.623 & 120.358 & 50.171 & -1.453 & -4.333 & 0 & 0 & 76.209 \\
\hline 4 & ZINC14726789 & 300.354 & 4 & 3 & 2.002 & -3.556 & 120.36 & 50.172 & -1.446 & -4.344 & 0 & 0 & 75.904 \\
\hline 5 & ZINC03589221 & 330.337 & 4 & 6 & 1.14 & -2.912 & 49.707 & 19.29 & -2.114 & -4.493 & 0 & 1 & 63.984 \\
\hline 6 & 35753 & 302.369 & 4 & 3 & 2.403 & -3.224 & 119.517 & 49.792 & -1.785 & -3.794 & 0 & 0 & 78.2 \\
\hline 7 & 663569 & 330.337 & 4 & 6 & 1.066 & -2.598 & 50.939 & 19.807 & -1.98 & -4.57 & 0 & 1 & 63.739 \\
\hline 8 & 747974 & 473.586 & 2 & 6.25 & 4.7 & -5.967 & 114.731 & 83.764 & -0.962 & -4.22 & 0 & 1 & 91.331 \\
\hline 9 & 706725 & 473.586 & 2 & 6.25 & 4.43 & -4.494 & 207.597 & 159.229 & -0.49 & -3.78 & 0 & 0 & 94.357 \\
\hline 10 & 32653 & 286.37 & 3 & 2.25 & 3.219 & -3.865 & 330.318 & 149.407 & -1.343 & -2.87 & 0 & 0 & 90.878 \\
\hline 11 & Reference OHT & 387.521 & 1 & 3.5 & 5.59 & -5.36 & 671.532 & 355.884 & -0.259 & -2.453 & 1 & 0 & 100 \\
\hline
\end{tabular}

MW (Molecular Weight of the molecule $)=(130.0$ to 725.0$)$

$\mathrm{HBD}=$ Hydrogen Bond Donor $=(0.0$ to 6.0$)$

HBA $=$ Hydrogen Bond Acceptor $=(2.0$ to 20.0$)$

QPlogP o/w = (Predicted octanol/water partition coefficient $)=(-2.0$ to 6.5$)$

QPlogS = (Predicted aqueous solubility, $\log S)=(-6.5$ to 0.5$)$

QPPCaco $=$ Predicted Caco-2 cell permeability in $\mathrm{nm} / \mathrm{s}$ (acceptable range: $<25$ is poor and $>500$ is great)

QPPMDCK = Predicted apparent MDCK cell permeability in $\mathrm{nm} / \mathrm{s}$.

QPlogBB = (Predicted brain/blood partition coefficient $)=(-3.0$ to 1.2$)$

$\mathrm{QP} \log \mathrm{KP}=($ Predicted skin permeability, $\log \mathrm{Kp})=(-8.0$ to -1.0$)$

Rule of $5=($ Number of violations of Lipinski's rule of five $)=($ maximum is 4$)$

Rule of 3 Violations $=($ Number of violations of Jorgensen's rule of three $)=($ maximum is 3$)$

\% $\mathrm{HOA}=$ Percentage of human oral absorption ( = > $80 \%$ is high, $<25 \%$ is low)

\subsection{Enrichment Calculation}

The virtual screening docking protocol was further evaluated by using an enrichment calculation process in terms of EF, ROC, and BEDROC metrics explained the area under ROC with 1.0, show the most active hits in ranking order based on quality. Since Trunchon and Bayly (2007) considered ROC with " $\geq 0.7$ " as a satisfying metric value to determine the highest precision and predicting ability of virtual screening docking protocol. Enrichment curve and values of ROC are tabulated in Fig. 3 and Table 4, respectively. 
Table 4

Evaluation of virtual screening protocol by Enrichment

\begin{tabular}{|lllll|}
\hline EF 1\% & RIE & ROC & $\begin{array}{l}\text { Enrichment } \\
\text { Matric }\end{array}$ & Value \\
& & & & \\
\hline 68 & 16.99 & 1.0 & BEDROC $(a=160.90)$ & 0.983 \\
& & & BEDROC $(a=20.00)$ & 0.981 \\
& & & BEDROC $(a=8.00)$ & 0.991 \\
\hline
\end{tabular}

EF1\%: Enrichment factor at 1\% of the decoy data set.

RIE: Robust initial enhancement.

ROC: Receiver operating characteristic curve value.

BEDROC: Boltzmann-enhanced discrimination of receiver operating characteristic.

\subsection{IFD}

Top 5 screened compounds (ZINC13377936, NCI35753, ZINC35465238, ZINC14726791, and NCI663569) along with co-crystallized ligand (Reference OHT) were taken forward in the IFD platform to confirm the best binding interaction within the receptor's binding site based on the highest docking score within the range from -11.314 to $-14.527 \mathrm{kcal} / \mathrm{mol}$, glide energy from -51.648 to $-62.526 \mathrm{kcal} / \mathrm{mol}$, IFD score from 532.191 to $-535.418 \mathrm{kcal} / \mathrm{mol}$ and interactive residues; shown in Table 5. To make protein-ligand interactions more understandable, the closed view of all the protein-ligand complexes, and their 2D interaction profile is presented in Fig. 4. 
Table 5

Induced fit docking result of the compounds examined from Virtual screening.

\begin{tabular}{|c|c|c|c|c|c|c|c|}
\hline $\begin{array}{l}\text { S. } \\
\text { No. }\end{array}$ & Compound ID & $\begin{array}{l}\text { Docking } \\
\text { Score } \\
\text { (kcal/ } \\
\text { mol) }\end{array}$ & $\begin{array}{l}\text { Glide } \\
\text { Energy } \\
\text { (kcal/ } \\
\text { mol) }\end{array}$ & $\begin{array}{l}\text { Total No. of H- } \\
\text { bond }\end{array}$ & $\begin{array}{l}\text { Interactive residues for } \mathrm{H} \text { - } \\
\text { bond }\end{array}$ & $\begin{array}{l}\text { Distance } \\
(\AA)\end{array}$ & $\begin{array}{l}\text { IFD } \\
\text { Score } \\
(\mathrm{kcal} / \mathrm{mol})\end{array}$ \\
\hline \multirow[t]{4}{*}{1} & ZINC13377936 & -14.527 & -62.526 & 05 & Thr347 & 1.85 & -535.418 \\
\hline & & & & & Asp351 & $1.61 \& 1.83$ & \\
\hline & & & & & Glu353 & 1.81 & \\
\hline & & & & & Trp383 & 1.90 & \\
\hline \multirow[t]{3}{*}{2} & $\mathrm{NCl} 35753$ & -14.017 & -51.648 & 04 & Leu346 & 1.75 & -534.132 \\
\hline & & & & & Glu353 & 1.66 & \\
\hline & & & & & Glu419 & $1.85 \& 2.03$ & \\
\hline \multirow[t]{4}{*}{3} & ZINC35465238 & -13.960 & -57.396 & 06 & Thr347 & 1.93 & -534.440 \\
\hline & & & & & Asp351 & $1.97 \& 2.06$ & \\
\hline & & & & & Glu353 & $1.75 \& 2.05$ & \\
\hline & & & & & Trp383 & 1.75 & \\
\hline \multirow[t]{2}{*}{4} & ZINC14726791 & -12.690 & -53.666 & 03 & Thr347 & 2.10 & -532.491 \\
\hline & & & & & Glu353 & $1.71 \& 1.78$ & \\
\hline \multirow[t]{4}{*}{5} & NCl663569 & -12.566 & -55.625 & 05 & Thr347 & 1.81 & -532.191 \\
\hline & & & & & Asp351 & $1.70 \& 1.79$ & \\
\hline & & & & & Glu353 & 1.78 & \\
\hline & & & & & Leu387 & 1.91 & \\
\hline 6 & Reference OHT & -11.314 & -56.076 & 01 & Glu353 & 1.80 & -532.671 \\
\hline
\end{tabular}

\subsection{MM-GBSA}

The binding free energy prediction was performed by a post-scoring method-MMGBSA for the evaluation of molecular docking process in both wild and mutant types which is applied to rank the best inhibition of targeted protein. In which, the value of MMGBSA ( $\triangle G$ bind) ranges from -13.802 to -65.359 , are shown in Table 4 and represented graphically in Fig. 5. Results were correlated along with docking score to design relevant drug-like potent inhibitors because the value $\Delta \mathrm{G}$ bind defines the greater binding affinity of the ligand to bind with the receptor. The outcome of MMGBSA was more supportive to understand the binding mode analysis of the ligand with the receptor to help in the generation of potent inhibitors against ERa.

Table 6

Results of binding free energy analysis.

\begin{tabular}{|llllll|}
\hline S. No. & Compound ID & $\Delta \mathbf{G}_{\text {Bind }{ }^{a}}$ & $\Delta \mathbf{G}_{\text {Coulomb }}{ }^{b}$ & $\Delta \mathbf{G}_{\text {Covalent }}{ }^{\mathrm{C}}$ & $\Delta \mathbf{G}_{\mathrm{VdW}}{ }^{\mathrm{d}}$ \\
\hline 1 & ZINC13377936 & -65.359 & -21.721 & 6.984 & -39.766 \\
\hline 2 & NCI35753 & -61.859 & -23.281 & 6.439 & -35.771 \\
\hline 3 & ZINC35465238 & -53.601 & -11.541 & 4.086 & -39.429 \\
\hline 4 & ZINC14726791 & -53.775 & -20.872 & 6.016 & -29.092 \\
\hline 5 & NCI663569 & -47.967 & -8.565 & 8.438 & -35.177 \\
\hline 6 & Reference OHT & -13.802 & -18.79 & 7.018 & -10.915 \\
\hline
\end{tabular}

Energies in kcal mol-1 
a- Free binding energy.

b- Coulomb energy contribution to the binding free energy.

c- Covalent energy contribution to the binding free energy

d-Vander Waals energy contribution to the binding free energy.

\subsection{MDS analysis}

MDS is an effective method for studying conformational and interaction stability under specific conditions of the physiological environment. Thus, the best protein-ligand complexes of final hits along with the reference were incorporated for simulation of the time of $50 \mathrm{~ns}$ using MDS to compare the structural behavior and flexibility. Analysis of root mean square deviation (RMSD), root mean square fluctuation (RMSF), the radius of gyration (RGYR) and hydrogen contacts were carried out to determine the conformational, as well the interaction stability of the receptor-ligand complexes. Figure 6 (A) shows that the RMSD graph of the backbone of all complexes are in the range of 0.2 to $0.6 \mathrm{~nm}$, in which the protein-ligand complexes with ZINC13377936 and NCI35753 have excellent stability in terms of RMSD as like known compound but the compoundZINC35465238 has shown significantly higher fluctuations. RMSF was calculated to get the residual stability of each complex. Figure 6 (B) of the RMSF graph represents that there are fewer changes in the residual level in all complexes. To find the compactness of protein's backbone atoms during the entire simulation period, the Radius of Gyration (RGYR) was calculated for all, represented in Fig. 6 (C), concentrate that all the complexes found to have less conformational changes and also, none of lost its compactness during the simulation, gives the significant results of stability in under an environmental condition. To determine the robust stability of hydrogen bond interactions between receptor-ligand, all complexes were monitored during trajectory analysis of 50 ns as shown in Fig. 6 (D) where compounds ZINC13377936, ZINC35465238 and NCl35753have revealed one hydrogen bond and a maximum of two hydrogens throughout 50ns with high stability. Butthe Reference OHT showed one hydrogen bond throughout 50 ns with less stability. Resulted MDS reveals that the compounds ZINC13377936 and NCl35753 has outstanding binding stability and lesser fluctuations. Thus, both hits may be future therapeutic agents for the inhibition of ERa.

\subsection{MM-PBSA}

Herein, the examination of the stability of binding compounds next to simulation in the form of free energy was calculated using an effective methodology-MM-PBSA, shown in Table 7.Results reveal that the ZINC13377936 (-183.517+/- $14.359 \mathrm{~kJ} \mathrm{~mol}-1)$ and NCl35753 (-174.542+/$70.874 \mathrm{~kJ} \mathrm{~mol}-1)$ compounds have less binding energy in comparison to ZINC35465238 (-128.596+/- $29.284 \mathrm{~kJ}$ mol - 1) and Reference OHT $(-117.642+/ 127.121 \mathrm{~kJ} \mathrm{~mol}-1)$. Likewise, the Van der Waal energies of ZINC13377936 (-217.606+/-14.362kJ mol - 1) and NCl35753 $(-184.590+/-59.838 \mathrm{~kJ} \mathrm{~mol}-1)$ compounds were less in comparison to others. Butthe electrostatic energies of NCl35753 $(-12.442+/-7.260 \mathrm{~kJ}$ $\mathrm{mol}-1)$ and ZINC35465238(-11.236+/-8.276kJ mol - 1) were high in negative than ZINC13377936 (-6.782+/- 9.359kJ mol - 1) and the SASA energy of the ZINC13377936, NCl35753, and ZINC35465238 have higher in negative value than reference one. The polar solvation energy contributes in a positive way to the total binding free energy. Therefore, the predicted binding free energy strongly support the docking results.

Table 7

Binding free energy of selected complexes using the MM-PBSA approach. All energy in KJ mol-1.

\begin{tabular}{|c|c|c|c|c|c|}
\hline Compound ID & Binding energy & van der Waal energy & Electrostatic energy & Polar solvation energy & SASA energy \\
\hline ZINC13377936 & $-183.517+/-14.359$ & $-217.606+/-14.362$ & $-6.782+/-9.359$ & $60.988+/-9.369$ & $-20.116+/-1.262$ \\
\hline $\mathrm{NCl} 35753$ & $-174.542+/-70.874$ & $-184.590+/-59.838$ & $-12.442+/-7.260$ & $39.016+/-14.783$ & $-16.526+/-5.340$ \\
\hline ZINC35465238 & $-128.596+/-29.284$ & $-160.807+/-28.977$ & $-11.236+/-8.276$ & $59.500+/-14.775$ & $-16.052+/-2.513$ \\
\hline Reference OHT & $-117.642+/ 127.121$ & $-132.132+/ 131.402$ & $-0.019+/-3.809$ & $26.399+/-32.592$ & $-11.891+/ 12.138$ \\
\hline
\end{tabular}

\subsection{PCA analysis}

PCA analysis was done for the top-scoring ligands (ZINC13377936, ZINC35465238, NCl35753 and Reference OHT) for analyzing the atomic positional fluctuations. It clearly shows that the protein complex with ligands ZINC13377936 and NCI35753 were highly stable during the entire simulation and occupied very little space in the system as compared with other complexes. This study suggests that both the complexes have more stable complex for inhibitory activity. The PCA analysis result is shown in Fig. 7. An overall result suggests the variable conformation of the protein in connection with the compounds, leading to a change in potential interactions. 


\subsection{Boiled Egg-Plot}

The boiled Egg plot is a statistically derived, expeditious and robust method to detect the passive gastrointestinal absorption. It is used to analyse the mechanism of small molecules which are being used for drug discovery in brain. The Boiled Egg plot is illustrated in Fig. 8 , employing four chief inhibitors - ZINC90797260, ZINC14726791, ZINC13377936 and ZINC35753. It shows that all the four inhibitors lie in whitespace dictating a high potential for GI absorption. Furthermore, studies have revealed that P-glycoproteins play a paramount role in actively transporting the chemically tailored compounds out of the cell. Comparative analysis divulged that the compounds ZINC90797260, ZINC14726791 and ZINC35753 are P-glycoprotein substrates, whereas ZINC13377936 is a non-substrate inhibitor.

The pharmacological properties and physiochemical properties of all the hit ligands including the optimization for gastrointestinal absorption are listed in Table 8. The four inhibitors were selected based on some molecular properties such as Water Partition Coefficient (WlogP) - the values should be less than 5 indicating mitigated level of toxicity, specific binding, and possible oral administration. The topological Polar Surface Area (TPSA) of all the selected compounds should be less than $100 \AA 2$ indicating a high possibility for complete absorption. Therefore, based on these criteria, it is inferred that the selected ligands form good interaction with the protein ESR1. Moreover, CYP450 (CYP1A2, CYP2C9, and CYP2C19) plays a major role acting as a substrate model in the metabolism cycle. Excretion is predicted based on the total clearance model and renal ESR1 substrate. The toxicity of drugs was predicted using AMES toxicity test and LD50 in rat. Hence, all four tested parameters show a positive result for selected inhibitors.

Table 8

Calculated physiochemical and pharmacological properties of the hits ligands.

\begin{tabular}{|lllllll|}
\hline Ligands & WlogP & TPSA $\left(\AA^{2}\right)$ & GI absorption & BBB permeant & P-gp substrate & CYP450 inhibitors \\
\hline ZINC90797260 & 2.95 & $90.15 \AA^{2}$ & Yes & No & Yes & CYP1A2,CYP2C9,CYP2C19 \\
\hline ZINC14726791 & 3.47 & $80.92 \AA^{2}$ & High & No & Yes & CYP1A2,CYP2C9 \\
\hline ZINC13377936 & 3.42 & $97.99 \AA^{2}$ & High & No & No & CYP1A2,CYP2C9,CYP2C19 \\
\hline ZINC35753 & 4.20 & $80.92 \AA^{2}$ & High & No & Yes & CYP1A2,CYP2C9,CYP2C19 \\
\hline
\end{tabular}

\subsection{Blood-Brain Barrier (BBB), HIA, Toxicity and LD50 comparison}

The blood-brain-barrier (BBB) is used to describe the peculiar properties of the microvasculature of the central nervous system (CNS). This is also used for maintaining the homeostasis for CNS.

Inhibitor permeability for BBB is a paramount prerequisite for drug discovery. BBB values for the four compounds have been listed in Table 9 and illustrated in Fig. 9; compound ZINC14726791 has highest BBB value -0.7154 , whereas ZINC90797260 has lowest 0.5319. All the four inhibitors for ESR1 predicted BBB + compounds and have been found with direct CNS activities and functions. Development of oral drug requires human intestinal absorption (HIA) spectra which plays a chief role in designing, optimizing the compounds. Absorption in the small intestine is a predominant fundamental process, highly used for drug bio-availability for oral administration. The two inhibitors ZINC90797260 and ZINC1472679 display $98.89 \%$ of Human Intestinal Absorption (HIA), and ZINC13377936 displays $84.33 \%$ HIA which is lowest among all.

The comparative ADMET analysis is listed in Table 9 for the selected inhibitors (ZINC90797260, ZINC14726791, ZINC13377936 and ZINC35753) which is based upon four parameters; Blood-brain-barrier (BBB), Human Intestinal Absorption (HIA), AMES Toxicity, and LD50. The required parameters are procured from the admetSAR database and tabulated according to their predicted values and properties. These four compounds are also graphically estimated using R-programming as illustrated in Fig. 9.

LD50 values in rats for the selected compounds dictate mitigated values for oral acute toxicity.

Compounds ZINC14726791 has 2.3403 LD50 value, while the other three compounds show similar LD50 absoption in the rat. No toxic effects are observed in the predicted In silico model for chronic oral toxicity. Based upon mutagenicity and AMES toxicity analysis, all the four compounds are found to be non-carcinogenic indicating a positive result. Due to expensive and laboriousness of the experimental tests, therefore it is highly necessary to develop a robust In silico method to predict the chemical mutagenicity. Thus, if the docked compounds are synthesized or studied in-vitro, they may behave as HIT since there is a good correlation between desired ESR1 protein and the compounds. 
Table 9

Comparative ADMET profile of the top four compounds.

\begin{tabular}{|lllllll|}
\hline Compound & BBB & HIA & CYPsubstrate /inhibition & AMES toxicity & Carcinogenicity & LD50 in rat \\
\hline ZINC90797260 & 0.5319 & 0.9889 & Non-substrate/inhibitor & 0.8275 & Non-carcinogenic & 1.9470 \\
\hline ZINC14726791 & 0.7154 & 0.9948 & Non-substrate/non-inhibitor & 0.8114 & Non-carcinogenic & 2.3403 \\
\hline ZINC13377936 & 0.6046 & 0.8433 & Non-substrate/non-inhibitor & 0.6399 & Non-carcinogenic & 1.8502 \\
\hline ZINC35753 & 0.5902 & 0.9626 & Non-substrate/non-inhibitor & 0.9119 & Non-carcinogenic & 1.9670 \\
\hline
\end{tabular}

\section{Material And Methods}

\subsection{System Configuration}

The presented In silico studies were performed using the specific software Schrodinger Drug Discovery Suite, NY and Gromacs installed on the CentOS Linux Enterprise version 7.0 with i5 processor, with 64 GB RAM. General workflow has represented in Fig. 10.

\subsection{Target selection and Protein Preparation}

X-ray crystal structure of the ERa in complex with 4-hydroxytamoxifen (OHT)(PDB Id: 3ERT [29] was selected for the present study by considering Resolution (1.9 $\AA$ ), and R-Value Free (0.262) as specific selection parameters from the Protein Data Bank[30-38]. Before proceeding to dock, the PDB structure was prepared using the Protein Preparation Wizard module(Schrodinger, Inc., LLC, New York, USA) by applying criteria like removal of water molecules, assigning bond orders, filling missing hydrogens, side chains \& loops, capping termini, selenomethionine to methionine reconversion, optimization and energy minimization using the OPLS-2005 force field with default settings[39-50].

\subsection{Preparation of Chemical libraries}

Ligand preparation was carried out with two discrete libraries (ZINC and NCI) using LigPrep module (Schrodinger, Inc., LLC, New York, USA) for better optimization, conversion of 2D to 3D ring conformers and ionization states tautomer states with an OPLS-2005 force field at the $\mathrm{pH}$ range of $7 \pm 2[39-45][46-58]$.

\subsection{Receptor grid generation and redocking}

Receptor grid was generated by picking the centroid OHT's in receptor using the Receptor Grid Generation Glide module(Schrodinger, Inc., LLC, New York, USA) in the XYZ coordinates $(X=31.91, Y=-1.8, Z=25.17)$ with default settings of the OPLS-2005 force field and the Vander Waal's radius scaling factor of $1 \AA$ with partial charge cut-off of $0.25 \AA[59-60]$. Further, the ligand 4-hydroxytamoxifen (OHT) was docked into the generated grid for confirming the interaction between protein and ligand using Glide XP (Schrodinger, Inc., LLC, New York, USA)before the execution of virtual screening[39-45].

\subsection{Structure-based virtual screening}

The trio of VS protocol of HTVS, SP, and XP from Glide module (Schrodinger, Inc., LLC, New York, USA) was applied successfully on prepared chemical libraries to obtain new drug-like candidates. The VS protocol acts to pre-filter the choice of molecules by Lipinski's rule of 5 and removing ligand with a reactive functional group. To explain the arbitrary number of torsional degrees of freedom by transitional and rotational parameters, all the molecules were put authoritarian state [61-74]. Later, the best ligand docking poses were filtered using glide docking based on a receptor grid and minimized with Van der Waals as well as electrostatic energies. Finally, top hits were retrieved with a higher score of docking, glide energy and binding mode analysis [75-82].

\subsection{ADME Prediction}

QikProp module (Schrodinger, Inc., LLC, New York, USA) was applied to generate ADME (adsorption, distribution, metabolism, and excretion) properties of the compounds before failing at a later stage of the drug discovery [71]. It analyzes the relevant properties of drug-likeness and pharmaceutical for all the hits like octanol/water (QlogP), aqueous solubility (QPlogS), brain/blood partition coefficient (QPlogBB), Predicted Caco-2 cell permeability (QPPCaco), Predicted apparent MDCK cell permeability (QPPMDCK), \% of Human Oral Absorption, molecular weight, number of hydrogen bond donors and acceptors. Besides, Jorgensen rule of three and Lipinski rule of five wasalso calculated. The QikProp module applies for the BOSS program with the OPLS-AA force field to perform Monte Carlo statistical mechanics simulation on various organic solutes in a periodic box of explicit water molecules [83-98]. 


\subsection{Enrichment calculation}

The combination of top hits compounds, co-crystallized inhibitor, and Schrödinger decoy sets (download from Schrödinger website) were taken into the platform of Glide XP docking and Enrichment calculator from Schrodinger, Inc., LLC, New York, USA(Toledo et al., 2014; Friesner et al., 2004; Truchon \& Bayly, 2007) for validating the docking protocol to identify an active one[99-104].

\subsection{IFD}

IFD protocol (Schrodinger, Inc., LLC, New York, USA) was implied on the selected top hits compounds from screening to analyze the best confirmation of the protein-ligand complex. Before proceeding to IFD, the receptor centroid ligand was selected for generating the grid box for the workspace ligand and finally, IFD was carried forward to generate 20 poses of each compound within the range of $5 \AA$ with default parameters of glide docking, constraints, prime energy refinement and re-docking [105-111].

\subsection{MM-GBSA - free binding energy calculation}

A prime module of Schrodinger Suite, MM-GBSA was selected to calculate the relative binding free energy for the improvement of the docking score of final IFD hits. It utilizes a surface generalized Born model for a more significant demonstration of a solvent surface area. The relative binding energy represents by $\Delta G_{\text {bind, }}$ with the following equation (Lyne et al., 2006)[112-120].

$\Delta \mathrm{G}_{\text {bind }}=\Delta \mathrm{E}+\Delta \mathrm{G}_{\text {solv }}+\Delta \mathrm{G}_{\mathrm{SA}}$

In which,

$\Delta \mathrm{G}_{\mathrm{bind}}=$ Binding Free Energy,

$\Delta \mathrm{E}=$ Difference of energy minimization between receptor-ligand complex \& the energies of receptor and ligand

Where, $\Delta E=E_{\text {complex }}-E_{\text {receptor }}-E_{\text {ligand }}$

$\Delta \mathrm{G}_{\text {solv }}=$ Difference of electrostatic solvation energy of the receptor-ligand complex\& the energies of receptor and ligand

Where, $\Delta \mathrm{G}_{\text {solv }}=\mathrm{G}_{\text {solv (complex) }}-\mathrm{G}_{\text {solv (receptor) }}-\mathrm{G}_{\text {solv (ligand) }}$

$\Delta \mathrm{G}_{\mathrm{SA}}=$ Difference of Surface area energies of the receptor-ligand complex\& the energies of receptor and ligand

Where, $\Delta \mathrm{G}_{\mathrm{SA}}=\mathrm{G}_{\mathrm{SA}(\text { complex) }}-\mathrm{G}_{\mathrm{SA} \text { (receptor) }}-\mathrm{G}_{\mathrm{SA} \text { (ligand) }}$

\subsection{Molecular Dynamics Simulation}

Groningen Machine for Chemicals Simulations (GROMACS) version 5.1.4 (http://www.gromacs.org/) was utilized in determining the structural dynamics of protein-ligand complexes (Jorgensen et al., 1996; Adcock et al., 2006). Top complexes of the screen along with reference, were taken for the MDS analysis. All the ligands' topologies were generated using a webserver - PRODRG (Schüttelkopf\& Van Aalten, 2004). The GROMOS force field is applied for performing MDS. Explicit water molecules were defined employing SPC (Simple Point Charge) model and a cubic period box with $1.0 \mathrm{~nm}$ distance (minimum) were set between protein and edge of the box. Following these, the protonation states of amino acid residues were set as per pH 7.0and the system was neutralized by adding counter ions [121-131].

Consequently, the energy minimization was performed for all protein-ligand complexes using the steepest descent energy approach $(1,000$ ps). Later on, the whole system was equilibrated by executing a position-restrained dynamics simulation (NVT and NPT) at $300 \mathrm{~K}$ for 300 ps. Finally, the equilibrated systems were subjected to MDStoanalyse the dynamics stability with $50 \mathrm{~ns}$ at a constant temperature of $300 \mathrm{~K}$, the pressure of $1 \mathrm{~atm}$, and an integration time step of 2 femtoseconds. Herein, other parameters like isothermal and isobaric coupling constants were set at $0.1 \mathrm{ps}$ and $2 \mathrm{ps}$, respectively, within the minimum distance between box edges and any protein atom equal to $2.0 \mathrm{~nm}$. Using Origin pro8 (Essmann et al., 1995) program, the statistical analysis like RMSD, RMSF, RGYR, and Hydrogen bond for each complex were analysed and respective graphs were plotted [132-140].

\subsection{MM-PBSA - free binding energy calculation}

The calculation of binding free energy of protein-ligand was carried out by using the MM-PBSA approach with the help of thegmmpbsa module in three steps. The potential energy in a vacuum is calculated in the previous step. Otherenergies (polar and non-polar solvation) 
were predicted in respective steps. Herein, the non-polar solvation energy was generated using the solvent-accessible surface area (SASA) model[141-148].

The free energy of binding is coming from the following theory:

$\Delta$ Gbinding = G-complex $-($ G-protein + G-ligand $)$

Where,G-complex = Total free energy of the protein-ligand complex

G-protein \&G-ligand = Total free energies of the separated form of protein and ligand in the solvent, respectively.

\subsection{Principal component analysis:}

Principal component analysis (PCA) or essential dynamics (ED) is one of the most important approaches to reveal the dynamic nature of proteins. It is a specific method to explain the functionally relevant motions of protein by the combination of local fluctuations and collective motions. The protocol was applied to build the covariance matrix with the extraction of concerted motion from all trajectories using backbone with g-covar and g-anaeig modules of GROMACS on selected screened compounds as well as reference inhibitor. In this process, the diagonalization of the covariance matrix generates a set of eigenvectors. A specific eigenvalue explains the energetic impact of the component on the motion [149-158].

\subsection{Boiled Egg-Plot:}

In the present investigation, we have used Boiled EGG-Plot to predict gastrointestinal absorption and brain penetration [16][61]. Aside from distinction to efficacy and toxicity, many new drug development failures are responsible for indigent pharmacokinetics and bioavailability. Gastrointestinal (GI) absorption and blood-brain access are two pharmacokinetics behaviors that estimate various drug development mechanisms. The Brain orlntestinal Estimated permeation method (BOILED-Egg) is expected as a factual predictive model that works by computing two parameters, i.e., the lipophilicity and polarity of the molecules. Contemporary predictions for both brain and intestinal permeation are accessed from the two same physicochemical descriptors and impartially rendered into the molecular design, owing to the speed, accuracy, conceptual simplicity and clear graphical output of the BOILED-Egg plot model. It also contains several parameters such as MW, TPSA, MLOGP, GI, and BBB, to revamp the BOILED-Egg plot. It can be enforced in various frameworks, from the filtering of chemical libraries at the initial steps of drug discovery and development to drug candidates' evaluation for further development.

\subsection{Blood-Brain Barrier (BBB), HIA, Toxicity and LD50 comparison}

The physiochemical properties of the top 4 compounds such as ZINC13377936, ZINC14726791, ZINC35753, ZINC90797260 were analyzed using SwissADME server, and the properties such as Blood-Brain Barrier (BBB), HIA, CYP inhibition, AMES toxicity carcinogenicity, LD50 in rat etc. were used for a comparative study using R programming. Abar plot was created using the ggplot library in $\mathrm{R}$ programming to compare the above properties [16][61].

\section{Conclusion}

As stated by numerous researches, $70 \%$ of breast cancers express the estrogen receptor, many of which are sensitive to ER inhibition. To summarize the role of ESR1 in breast cancer, our study focused on identifying effective and potent inhibitors of ERa using rational in silico approaches. The key concept of structural features for ERa inhibition has been furnished by applying a combined molecular docking, virtual screening, and ADME, MMGBSA, dynamics simulation, MMPBSA and PCA studies. All the 20 compounds have shown significant interaction with active site residues of the 4-hydroxytamoxifen (OHT) protein. As a result of the docking study, we identified ZINC13377936, NCI35753, ZINC35465238, ZINC14726791, and NCl663569) as the top 5 screened compounds. Further, our Molecular Dynamics results suggest that the potent compounds ZINC13377936 and NCI35753 show the highly stable hydrogen bonding with the common residues of Glu353, Leu387, and Arg394. Moreover, PCA analysis suggests that both the complexes have a more stable complex for inhibitory activity. Thus, these results have important implications in future breast cancer diagnostics and treatments. We are hopeful that these notable findings could be a potent inhibitor of ERa, which may execute further for experimental investigations.

\section{Abbreviations}

ADME - Absorption, Distribution, Metabolism, Excretion

HTVS - High Throughput Virtual Screening

Page $13 / 30$ 
IFD - Induced Fit Docking

MDS - Molecular Dynamics Simulation

MM-GBSA - Molecular Mechanics energies combined with the Generalized Born and Surface Area continuum solvation

MM-BSA - Molecular mechanics-Poisson Boltzmann surface area

OPLS - Optimized Potentials for Liquid Simulations

RGYR - Radius of Gyration

RMSD - Root Mean Square Deviation

RMSF - Root-Mean-Square Fluctuation

SP - Standard Precision

VS - Virtual Screening

XP - Extra Precision

\section{Declarations}

\section{AUTHOR CONTRIBUTIONS}

IC, UP, AB, MM, LS was involved in Molecular docking, Molecular Dynamics Simulation, Writing - review \& editing. KS, ASP, VPM, LP were contributed towards Inhibitors collection, Data curation, Formal analysis, Validation, Visualization. UP, IJ, AN was involved in Molecular dynamic simulation. RS, SA, SA, KJA and TH were involved in Molecular Docking, ADMET analysis, R Programming analysis, Writing review \& editing. AN, and SKS were contributed in investigation, supervision, writing - review \& editing.

\section{Conflicts of interest/Competing interests:}

The authors declare that they have no conflict of interest.

\section{AVAILABILITY OF DATA AND MATERIALS:}

Not applicable.

Code Availability:

Code will be provided as per the request

\section{ETHICS APPROVAL AND CONSENT TO PARTICIPATE:}

Not applicable. 
No animals/humans were used in the studies that are the basis of this research.

\section{Acknowledgements:}

1. This work was supported by Taif University Researchers Supporting Program (project number: TURSP-2020/128), Taif University, Saudi Arabia.

2. The authors are grateful to the Deanship of Scientific Research, King Saud University for funding through Vice Deanship of Scientific Research Chairs.

3. SKS thank Alagappa University, Department of Biotechnology (DBT), New Delhi (No. BT/PR8138/BID/7/458/2013, dated 23rd May 2013), DST-PURSE $2^{\text {nd }}$ Phase Programme Order No. SR/PURSE Phase 2/38 (G dated 21.02.2017 and FIST (SR/FST/LSI 667/2016),MHRD RUSA 1.0 and RUSA 2.0 for providing the financial assistance. UP gratefully acknowledge Indian Council of Medical Research (ISRM/11/(19)/2017, dated: 09.08.2018).

\section{Conflict of Interest:}

The Author(s) declare that there is no conflict of interest.

\section{References}

1. Sheng X, Guo Y, Lu Y (2017) Prognostic role of methylated GSTP1, p16, ESR1 and PITX2 in patients with breast cancer: A systematic meta-analysis under the guideline of PRISMA. Medicine, 96(28)

2. Ding SL, Yu JC, Chen ST, Hsu GC, Hsu HM, Ho JY, Wu PE (2010) Diverse associations between ESR1 polymorphism and breast cancer development and progression. Clin Cancer Res 16(13):3473-3484

3. Osborne CK, Schiff R (2005) Estrogen-receptor biology: continuing progress and therapeutic implications. J Clin Oncol 23(8):1616-1622

4. Lau WS, Chen WF, Chan RYK, Guo DA, Wong MS (2009) Mitogen-activated protein kinase (MAPK) pathway mediates the oestrogen-like activities of ginsenoside Rg1 in human breast cancer (MCF-7) cells. Br J Pharmacol 156(7):1136-1146

5. Kahn SA, Rogers MA, Khurana KK et al (1998) Estrogen receptor expression in benign breast epithelium and breast cancer risk. J Natl Cancer Inst 90:37-42

6. Holst, F., Stahl, P. R., Ruiz, C., Hellwinkel, O., Jehan, Z., Wendland, M., ... Sauter,G. (2007). Estrogen receptor alpha (ESR1) gene amplification is frequent in breast cancer. Nature genetics, 39(5), 655-660

7. Sharma K, Patidar K, Ali MA, Patil P, Goud H, Hussain T, Nayarisseri A, Singh SK (2018) Structure-based virtual screening for the identification of high affinity compounds as potent VEGFR2 inhibitors for the treatment of renal cell carcinoma. Curr Top Med Chem 18(25):2174-2185

8. Sahila MM, Babitha PP, Bandaru S, Nayarisseri A, Doss VA (2015) Molecular docking based screening of GABA (A) receptor inhibitors from plant derivatives. Bioinformation 11(6):280

9. Vuree S, Dunna NR, Khan IA, Alharbi KK, Vishnupriya S, Soni D, Shah P, Chandok H, Yadav M, Nayarisseri A (2013) Pharmacogenomics of drug resistance in Breast Cancer Resistance Protein (BCRP) and its mutated variants. J Pharm Res 6(7):791-798

10. Monteiro AFM, Viana JDO, Nayarisseri A, Zondegoumba EN, Mendonça Junior FJB, Scotti MT, Scotti L (2018) Computational studies applied to flavonoids against alzheimer's and parkinson's diseases. Oxidative medicine and cellular longevity, 2018

11. Bandaru S, GangadharanSumithnath T, Sharda S, Lakhotia S, Sharma A, Jain A, Hussain T, Nayarisseri A, Singh K, S (2017) Helix-Coil transition signatures B-Raf V600E mutation and virtual screening for inhibitors directed against mutant B-Raf. Curr Drug Metab 18(6):527-534

12. Kelotra A, Gokhale SM, Kelotra S, Mukadam V, Nagwanshi K, Bandaru S, Nayarisseri A, Bidwai A (2014) Alkyloxy carbonyl modified hexapeptides as a high affinity compounds for Wnt5A protein in the treatment of psoriasis. Bioinformation 10(12):743

13. Basak SC, Nayarisseri A, González-Díaz H, Bonchev D (2016) Editorial (Thematic Issue: chemoinformatics models for pharmaceutical design, part 1). 22(33):5041-5042

14. Basak SC, Nayarisseri A, González-Díaz H, Bonchev D (2016) Editorial (Thematic Issue: Chemoinformatics models for pharmaceutical design, part 2). 22(34):5177-5178 
15. Prajapati L, Khandelwal R, Yogalakshmi KN, Munshi A, Nayarisseri A (2020) Computer-aided Structure prediction of Bluetongue Virus coat protein VP2 assisted by Optimized Potential for Liquid Simulations (OPLS). Curr Top Med Chem 20(19):1720-1732

16. Nayarisseri A, Khandelwal R, Madhavi M, Selvaraj C, Panwar U, Sharma K, Hussain T, Singh SK (2020) Shape-based machine learning models for the potential novel COVID-19 protease inhibitors assisted by molecular dynamics simulation. Curr Top Med Chem 20(24):2146-2167

17. Nayarisseri A (2020) Most Promising Compounds for Treating COVID-19 and Recent Trends in Antimicrobial \& Antifungal Agents. Curr Top Med Chem 20(24):2119-2125

18. Pochetti G, Mitro N, Lavecchia A, Gilardi F, Besker N, Scotti E, Aschi M, Re N, Fracchiolla G, Laghezza A, Tortorella P (2010) Structural insight into peroxisome proliferator-activated receptor $\mathrm{Y}$ binding of two ureidofibrate-like enantiomers by molecular dynamics, cofactor interaction analysis, and site-directed mutagenesis. J Med Chem 53(11):4354-4366

19. Soares Rodrigues GC, dos Santos Maia M, Muratov EN, Scotti L, Scotti MT (2020) Quantitative Structure-Activity Relationship Modeling and Docking of Monoterpenes with Insecticidal Activity Against Reticulitermes chinensis Snyder and Drosophila melanogaster. J Agric Food Chem 68(16):4687-4698

20. Wang Y, Wang LF, Zhang LL, Sun HB, Zhao J (2020) Molecular mechanism of inhibitor bindings to bromodomain-containing protein 9 explored based on molecular dynamics simulations and calculations of binding free energies. SAR QSAR Environ Res 31(2):149-170

21. Wang LF, Wang Y, Yang ZY, Zhao J, Sun HB, Wu SL (2020) Revealing binding selectivity of inhibitors toward bromodomain-containing proteins 2 and 4 using multiple short molecular dynamics simulations and free energy analyses. SAR QSAR Environ Res 31(5):373-398

22. Brugnoni M, Scotti A, Rudov AA, Gelissen AP, Caumanns T, Radulescu A, Eckert T, Pich A, Potemkin II, Richtering W (2018) Swelling of a responsive network within different constraints in multi-thermosensitive microgels. Macromolecules 51(7):2662-2671

23. Montanari R, Saccoccia F, Scotti E, Crestani M, Godio C, Gilardi F, Loiodice F, Fracchiolla G, Laghezza A, Tortorella P, Lavecchia A (2008) Crystal structure of the peroxisome proliferator-activated receptor $\mathrm{Y}$ (PPARY) ligand binding domain complexed with a novel partial agonist: a new region of the hydrophobic pocket could be exploited for drug design. J Med Chem 51(24):7768-7776

24. Wang J, Qian Y, Li L, Qiu X (2020) Atomic Force Microscopy and Molecular Dynamics Simulations for Study of Lignin Solution SelfAssembly Mechanisms in Organic-Aqueous. Solvent Mixtures ChemSusChem 13(17):4420-4427

25. Liguori N, Croce R, Marrink SJ, Thallmair S (2020) Molecular dynamics simulations in photosynthesis. Photosynth Res 144(2):273-295

26. Kuzmanic A, Bowman GR, Juarez-Jimenez J, Michel J, Gervasio FL (2020) Investigating cryptic binding sites by molecular dynamics simulations. Acc Chem Res 53(3):654-661

27. Klesse G, Rao S, Tucker SJ, Sansom MS (2020) Induced polarization in molecular dynamics simulations of the 5-HT3 receptor channel. J Am Chem Soc 142(20):9415-9427

28. Shiau AK, Barstad D, Loria PM, Cheng L, Kushner PJ, Agard DA, Greene GL (1998) The structural basis of estrogen receptor/coactivator recognition and the antagonism of this interaction by tamoxifen. Cell 95(7):927-937

29. Berman H, Henrick K, Nakamura H, Markley JL (2007) The worldwide Protein Data Bank (wwPDB): ensuring a single, uniform archive of PDB data. Nucleic Acids Res 35(suppl1):D301-D303

30. Natchimuthu V, Bandaru S, Nayarisseri A, Ravi S (2016) Design, synthesis and computational evaluation of a novel intermediate salt of $\mathrm{N}$-cyclohexyl-N-(cyclohexylcarbamoyl)-4-(trifluoromethyl) benzamide as potential potassium channel blocker in epileptic paroxysmal seizures. Comput Biol Chem 64:64-73

31. Bandaru S, Alvala M, Akka J, Sagurthi SR, Nayarisseri A, Kumar Singh S, Mundluru P, H (2016) Identification of small molecule as a high affinity $\beta 2$ agonist promiscuously targeting wild and mutated (Thr164lle) $\beta 2$ adrenergic receptor in the treatment of bronchial asthma. Curr Pharm Design 22(34):5221-5233

32. Majhi M, Ali MA, Limaye A, Sinha K, Bairagi P, Chouksey M, Shukla R, Kanwar N, Hussain T, Nayarisseri A, Singh SK (2018) An in silico investigation of potential EGFR inhibitors for the clinical treatment of colorectal cancer. Curr Top Med Chem 18(27):2355-2366

33. Khandelwal R, Chauhan AP, Bilawat S, Gandhe A, Hussain T, Hood EA, Nayarisseri A, Singh SK (2018) Structure-based virtual screening for the identification of high-affinity small molecule towards STAT3 for the clinical treatment of osteosarcoma. Curr Top Med Chem 18(29):2511-2526

34. Sinha K, Majhi M, Thakur G, Patidar K, Sweta J, Hussain T, Nayarisseri A, Singh SK (2018) Computer-aided drug designing for the identification of high-affinity small molecule targeting cd20 for the clinical treatment of chronic lymphocytic leukemia (CLL). Curr Top Med Chem 18(29):2527-2542

35. Chandrakar B, Jain A, Roy S, Gutlapalli VR, Saraf S, Suppahia A, Verma A, Tiwari A, Yadav M, Nayarisseri A (2013) Molecular modeling of Acetyl-CoA carboxylase (ACC) from Jatropha curcas and virtual screening for identification of inhibitors. J Pharm Res 6(9):913-918 
36. Nayarisseri A, Moghni SM, Yadav M, Kharate J, Sharma P, Chandok KH, Shah KP (2013) In silico investigations on HSP90 and its inhibition for the therapeutic prevention of breast cancer. J Pharm Res 7(2):150-156

37. Udhwani T, Mukherjee S, Sharma K, Sweta J, Khandekar N, Nayarisseri A, Singh SK (2019) Design of PD-L1 inhibitors for lung cancer. Bioinformation 15(2):139

38. Schrodinger LLC (2009) NY, USA,

39. LigPrep, Schrodinger LLC Ney York, NY

40. Prime S LLC, Ney York, NY

41. Protein P, Wizard Schrodinger, LLC, Ney York, NY

42. Qikprop S LLC, Ney York, NY

43. Shukla P, Khandelwal R, Sharma D, Dhar A, Nayarisseri A, Singh SK (2019) Virtual screening of IL-6 inhibitors for idiopathic arthritis. Bioinformation 15(2):121

44. Nayarisseri A, Hood EA (2018) Advancement in microbial cheminformatics. Curr Top Med Chem 18(29):2459-2461

45. Jain D, Udhwani T, Sharma S, Gandhe A, Reddy PB, Nayarisseri A, Singh SK (2019) Design of novel JAK3 Inhibitors towards Rheumatoid Arthritis using molecular docking analysis. Bioinformation 15(2):68

46. Nayarisseri A, Singh SK (2019) Functional inhibition of VEGF and EGFR suppressors in cancer treatment. Curr Top Med Chem 19(3):178-179

47. Gokhale P, Chauhan APS, Arora A, Khandekar N, Nayarisseri A, Singh SK (2019) FLT3 inhibitor design using molecular docking based virtual screening for acute myeloid leukemia. Bioinformation 15(2):104

48. Ali MA, Vuree S, Goud H, Hussain T, Nayarisseri A, Singh SK (2019) Identification of high-affinity small molecules targeting gamma secretase for the treatment of Alzheimer's disease. Curr Top Med Chem 19(13):1173-1187

49. Patidar K, Panwar U, Vuree S, Sweta J, Sandhu MK, Nayarisseri A, Singh SK (2019) An in silico approach to identify high affinity small molecule targeting m-TOR inhibitors for the clinical treatment of breast cancer. Asian Pac J cancer prevention: APJCP 20(4):1229

50. Pandey N, Yadav M, Nayarisseri A, Ojha M, Prajapati J, Gupta S (2013) Cross evaluation of different classes of alpha-adrenergic receptor antagonists to identify overlapping pharmacophoric requirements. J Pharm Res 6(1):173-178

51. Marunnan SM, Pulikkal BP, Jabamalairaj A, Bandaru S, Yadav M, Nayarisseri A, Doss VA (2017) Development of MLR and SVM aided QSAR models to identify common SAR of GABA uptake herbal inhibitors used in the treatment of Schizophrenia. Curr Neuropharmacol 15(8):1085-1092

52. Sweta, J., Khandelwal, R., Srinitha, S., Pancholi, R., Adhikary, R., Ali, M. A., ...Singh, S. K. (2019). Identification of high-affinity small molecule targeting IDH2 for the clinical treatment of acute myeloid leukemia. Asian Pacific journal of cancer prevention: APJCP, 20(8), 2287

53. Nayarisseri A (2019) Prospects of utilizing computational techniques for the treatment of human diseases. Curr Top Med Chem 19(13):1071-1074

54. Shelley JC, Cholleti A, Frye LL, Greenwood JR, Timlin MR, Uchimaya M (2007) Epik: a software program for pK a prediction and protonation state generation for drug-like molecules. J Comput Aided Mol Des 21(12):681-691

55. Baby K, Maity S, Mehta CH, Suresh A, Nayak UY, Nayak Y (2020) Targeting SARS-CoV-2 main protease: A computational drug repurposing study. Archives of medical research

56. Gahlawat, A., Kumar, N., Kumar, R., Sandhu, H., Singh, I. P., Singh, S., ... Garg, P.(2020). Structure-based virtual screening to discover potential lead molecules for the SARS-CoV-2 main protease. Journal of chemical information and modeling

57. Xu, X., Mao, L., Xu, W., Tang, W., Zhang, X., Xi, B., ... Zhang, L. (2016). AC0010,an irreversible EGFR inhibitor selectively targeting mutated EGFR and overcoming T790M-induced resistance in animal models and lung cancer patients. Molecular cancer therapeutics,15(11), 2586-2597

58. Selvaraj C, Panwar U, Dinesh DC, Boura E, Singh P, Dubey VK, Singh SK (2020) Microsecond MD Simulation and Multiple-Confirmation Virtual Screening to Identify Potential Anti-COVID-19 Inhibitors Against SARS-CoV-2 Main Protease. Front Chem 8:1179

59. Umesh, Kundu D, Selvaraj C, Singh SK, Dubey VK (2020) Identification of new anti-nCoV drug chemical compounds from Indian spices exploiting SARS-CoV-2 main protease as target.Journal of Biomolecular Structure and Dynamics,1-7

60. Sharda, S., Khandelwal, R., Adhikary, R., Sharma, D., Majhi, M., Hussain, T., ... Singh,S. K. (2019). A Computer-Aided Drug Designing for Pharmacological Inhibition of Mutant ALK for the Treatment of Non-small Cell Lung Cancer. Current topics in medicinal chemistry, 19(13), 1129-1144

Page $17 / 30$ 
61. Limaye A, Sweta J, Madhavi M, Mudgal U, Mukherjee S, Sharma S, Hussain T, Nayarisseri A, Singh SK (2019) In silico insights on gd2: a potential target for pediatric neuroblastoma. Curr Top Med Chem 19(30):2766-2781

62. Nayarisseri A, Yadav M (2015) Editorial (Thematic Issue: Mechanistics in drug design-experimental molecular biology vs. molecular modeling). Curr Top Med Chem 15(1):3-4

63. Kleandrova VV, Scotti MT, Scotti L, Nayarisseri A, Speck-Planche A (2020) Cell-based multi-target QSAR model for design of virtual versatile inhibitors of liver cancer cell lines. SAR QSAR Environ Res 31(11):815-836

64. Nayarisseri A (2020) Experimental and computational approaches to improve binding affinity in chemical biology and drug discovery. Curr Top Med Chem 20(19):1651-1660

65. Kaushik AC, Kumar S, Wei DQ, Sahi S (2018) Structure based virtual screening studies to identify novel potential compounds for GPR142 and their relative dynamic analysis for study of type 2 diabetes. Frontiers in chemistry, 6,23

66. Toledo Warshaviak D, Golan G, Borrelli KW, Zhu K, Kalid O (2014) Structure-based virtual screening approach for discovery of covalently bound ligands. J Chem Inf Model 54(7):1941-1950

67. Lyne PD (2002) Structure-based virtual screening: an overview. Drug Discovery Today 7(20):1047-1055

68. Dighe SN, Deora GS, De la Mora E, Nachon F, Chan S, Parat MO, Brazzolotto X, Ross BP (2016) Discovery and structure-activity relationships of a highly selective butyrylcholinesterase inhibitor by structure-based virtual screening. J Med Chem 59(16):7683-7689

69. Schrödinger L (2011) QikProp:Rapid ADME predictions of drug candidates

70. Lionta E, Spyrou G, Vassilatis K, Cournia Z (2014) Structure-based virtual screening for drug discovery: principles, applications and recent advances. Curr Top Med Chem 14(16):1923-1938

71. Vidler LR, Filippakopoulos P, Fedorov O, Picaud S, Martin S, Tomsett M, Woodward H, Brown N, Knapp S, Hoelder S (2013) Discovery of novel small-molecule inhibitors of BRD4 using structure-based virtual screening. J Med Chem 56(20):8073-8088

72. Pitt WR, Calmiano MD, Kroeplien B, Taylor RD, Turner JP, King MA (2013) Structure-based virtual screening for novel ligands. ProteinLigand Interactions. Humana Press, Totowa, NJ, pp 501-519

73. Choudhary S, Malik YS, Tomar S (2020) Identification of SARS-CoV-2 cell entry inhibitors by drug repurposing using in silico structurebased virtual screening approach. Front Immunol 11:1664

74. Adhikary R, Khandelwal R, Hussain T, Nayarisseri A, Singh SK (2020) May Structural Insights into the Molecular Design of ROS1 Inhibitor for the Treatment of Non-Small Cell Lung Cancer (NSCLC). Current Computer-aided Drug Design. DOI: 10.2174/1573409916666200504105249

75. Aher A, Udhwani T, Khandelwal R, Limaye A, Hussain T, Nayarisseri A, Singh SK (2020) In silico insights on IL-6: A potential target for multicentric castleman disease. Curr Comput-Aided Drug Design 16(5):641-653

76. Qureshi S, Khandelwal R, Madhavi M et al (2021 Jan) A Multi-Target Drug Designing for BTK, MMP9, Proteasome And TAK1 for the clinical treatment of Mantle Cell Lymphoma. Curr Top Med Chem. DOI: 10.2174/1568026621666210119112336

77. Yadav, M., Khandelwal, R., Mudgal, U., Srinitha, S., Khandekar, N., Nayarisseri, A.,... Singh, S. K. (2019). Identification of Potent VEGF Inhibitors for the Clinical Treatment of Glioblastoma, A Virtual Screening Approach. Asian Pacific journal of cancer prevention:APJCP, 20(9), 2681

78. Nayarisseri A, Khandelwal R, Tanwar P, Madhavi M, Sharma D, Thakur G, Speck-Planche A, Singh SK (2021) Artificial Intelligence, Big data and Machine Learning approaches in Precision Medicine \& Drug Discovery. Curr Drug Targets. Jan 4. doi: 10.2174/1389450122999210104205732. Epub ahead of print. PMID: 33397265

79. Francisco JB, Mendonça-Junior MT, Scotti, AnurajNayarisseri, Ernestine NT, Zondegoumba L, Scotti (2019) "Natural Bioactive Products with Antioxidant Properties Useful in Neurodegenerative Diseases", Oxidative Medicine and Cellular Longevity, vol. Article ID 7151780,2 pages, 2019. https://doi.org/10.1155/2019/7151780

80. Celik I, Erol M, TemizArpaci O, SezerSenol F, Erdogan Orhan I (2020) Evaluation of activity of some 2, 5-disubstituted benzoxazole derivatives against acetylcholinesterase, butyrylcholinesterase and tyrosinase: ADME prediction, DFT and comparative molecular docking studies.Polycyclic Aromatic Compounds,1-12

81. Pawar VS, Lokwani DK, Bhandari SV, Bothara KG, Chitre TS, Devale TL, Modhave NS, Parikh JK (2011) (2011). Design, docking study and ADME prediction of Isatin derivatives as anti-HIV agents. Medicinal chemistry research, 20(3), 370-380

82. Dincel ED, Gürsoy E, Yilmaz-Ozden T, Ulusoy-Güzeldemirci N (2020) Antioxidant activity of novel imidazo [2, 1-b] thiazole derivatives: Design, synthesis, biological evaluation, molecular docking study and in silico ADME prediction. Bioorg Chem 103:104220

83. Kumar S, Saini V, Maurya IK, Sindhu J, Kumari M, Kataria R, Kumar V (2018) Design, synthesis, DFT, docking studies and ADME prediction of some new coumarinyl linked pyrazolylthiazoles: Potential standalone or adjuvant antimicrobial agents.PloS one, 13(4), e0196016

Page $18 / 30$ 
84. Erol M, Celik I, Temiz-Arpaci O, Goker H, Kaynak-Onurdag F, Okten S (2020) Synthesis, molecular docking and ADME prediction of some new benzimidazole carboxamidines derivatives as antimicrobial agents. Med Chem Res 29(11):2028-2038

85. Kashid AM, Dube PN, Alkutkar PG, Bothara KG, Mokale SN, Dhawale SC (2013) Synthesis, biological screening and ADME prediction of benzylindole derivatives as novel anti-HIV-1, anti-fungal and anti-bacterial agents. Med Chem Res 22(10):4633-4640

86. Kalin TN, Kilic D, Arslan F, Colak O, Altundas A (2020) Synthesis, molecular modeling studies, ADME prediction of arachidonic acid carbamate derivatives, and evaluation of their acetylcholinesterase activity. Drug Dev Res 81(2):232-241

87. Kumar A, Rathi E, Kini SG (2019) E-pharmacophore modelling, virtual screening, molecular dynamics simulations and in-silico ADME analysis for identification of potential E6 inhibitors against cervical cancer. J Mol Struct 1189:299-306

88. Bhatt JD, Chudasama CJ, Patel KD (2015) Pyrazole clubbed triazolo [1, 5-a] pyrimidine hybrids as an anti-tubercular agents: Synthesis, in vitro screening and molecular docking study. Bioorg Med Chem 23(24):7711-7716

89. Dofe VS, Sarkate AP, Lokwani DK, Shinde DB, Kathwate SH, Gill CH (2017) Novel O-Alkylated Chromones as Antimicrobial Agents: Ultrasound Mediated Synthesis, Molecular Docking and ADME Prediction. J Heterocycl Chem 54(5):2678-2685

90. Malik R, Mehta P, Srivastava S, Choudhary BS, Sharma M (2017) Pharmacophore modeling, 3D-QSAR, and in silico ADME prediction of N-pyridyl and pyrimidine benzamides as potent antiepileptic agents. J Recept Signal Transduction 37(3):259-266

91. da Silva Hage-Melim, L. I., Federico, L. B., de Oliveira, N. K. S., Francisco, V.C. C., Correia, L. C., de Lima, H. B., ... Francischini, I. A. G. (2020). Virtual screening,ADME/Tox predictions and the drug repurposing concept for future use of old drugs against the COVID-19. Life Sciences, 256, 117963

92. Upadhyay S, Tripathi AC, Paliwal S, Saraf SK (2017) 2-pyrazoline derivatives in neuropharmacology: Synthesis, ADME prediction, molecular docking and in vivo biological evaluation. EXCLI J 16:628

93. Pandey RK, Narula A, Naskar M, Srivastava S, Verma P, Malik R, Shah P, Prajapati VK (2017) Exploring dual inhibitory role of febrifugine analogues against Plasmodium utilizing structure-based virtual screening and molecular dynamic simulation. J Biomol Struct Dynamics 35(4):791-804

94. Sadhasivam A, Vetrivel U (2019) Identification of potential drugs targeting L, L-diaminopimelate aminotransferase of Chlamydia trachomatis: An integrative pharmacoinformatics approach. J Cell Biochem 120(2):2271-2288

95. Zakerali T, Shahbazi S (2018) Rational druggability investigation toward selection of lead molecules: impact of the commonly used spices on inflammatory diseases. Assay Drug Dev Technol 16(7):397-407

96. Suma KB, Kumari A, Shetty D, Fernandes E, Chethan DV, Jays J, Murahari M (2020) Structure based pharmacophore modelling approach for the design of azaindole derivatives as DprE1 inhibitors for tuberculosis. J Mol Graph Model 101:107718

97. Sukumar N, Pask JE (2009) Classical and enriched finite element formulations for Bloch-periodic boundary conditions. Int J Numer Methods Eng 77(8):1121-1138

98. Rohini K, Ramanathan K, Shanthi V (2019) Multi-dimensional screening strategy for drug repurposing with statistical framework-a new road to influenza drug discovery. Cell Biochem Biophys 77(4):319-333

99. Halgren TA, Murphy RB, Friesner RA, Beard HS, Frye LL, Pollard WT, Banks JL (2004) Glide: a new approach for rapid, accurate docking and scoring. 2. Enrichment factors in database screening. J Med Chem 47(7):1750-1759

100. Sastry GM, Adzhigirey M, Day T, Annabhimoju R, Sherman W (2013) Protein and ligand preparation: parameters, protocols, and influence on virtual screening enrichments. J Comput Aided Mol Des 27(3):221-234

101. Lenselink EB, Beuming T, Sherman W, van Vlijmen HW, IJzerman AP (2014) Selecting an optimal number of binding site waters to improve virtual screening enrichments against the adenosine A2A receptor. J Chem Inf Model 54(6):1737-1746

102. Verma P, Tiwari M, Tiwari V (2018) In silico high-throughput virtual screening and molecular dynamics simulation study to identify inhibitor for AdeABC efflux pump of Acinetobacter baumannii. J Biomol Struct Dynamics 36(5):1182-1194

103. Sherman W, Beard HS, Farid R (2006) Use of an induced fit receptor structure in virtual screening. Chem Biol Drug Des 67(1):83-84

104. Bhachoo J, Beuming T (2017) Investigating protein-peptide interactions using the Schrödinger computational suite.Modeling peptideprotein interactions,235-254

105. Deb PK, Chandrasekaran B, Mailavaram R, Tekade RK, Jaber AMY (2019) Molecular modeling approaches for the discovery of adenosine A2B receptor antagonists: current status and future perspectives. Drug Discovery Today 24(9):1854-1864

106. Vanajothi R, Hemamalini V, Jeyakanthan J, Premkumar K (2020) Ligand-based pharmacophore mapping and virtual screening for identification of potential discoidin domain receptor 1 inhibitors. J Biomol Struct Dynamics 38(9):2800-2808

107. Politi A, Durdagi S, Moutevelis-Minakakis P, Kokotos G, Mavromoustakos T (2010) Development of accurate binding affinity predictions of novel renin inhibitors through molecular docking studies. J Mol Graph Model 29(3):425-435

Page $19 / 30$ 
108. Liu K, Kokubo H (2017) Exploring the stability of ligand binding modes to proteins by molecular dynamics simulations: a cross-docking study. J Chem Inf Model 57(10):2514-2522

109. Munnaluri R, Sivan SK, Manga V (2015) Molecular docking and MM/GBSA integrated protocol for designing small molecule inhibitors against HIV-1 gp41. Med Chem Res 24(2):829-841

110. Lyne PD, Lamb ML, Saeh JC (2006) Accurate prediction of the relative potencies of members of a series of kinase inhibitors using molecular docking and MM-GBSA scoring. J Med Chem 49(16):4805-4808

111. Peddi SR, Sivan SK, Manga V (2018) Molecular dynamics and MM/GBSA-integrated protocol probing the correlation between biological activities and binding free energies of HIV-1 TAR RNA inhibitors. J Biomol Struct Dynamics 36(2):486-503

112. Shen M, Zhou S, Li Y, Pan P, Zhang L, Hou T (2013) Discovery and optimization of triazine derivatives as ROCK1 inhibitors: molecular docking, molecular dynamics simulations and free energy calculations. Mol Biosyst 9(3):361-374

113. Bathini R, Sivan SK, Fatima S, Manga V (2016) Molecular docking, MM/GBSA and 3D-QSAR studies on EGFR inhibitors. J Chem Sci 128(7):1163-1173

114. Pandey RK, Kumbhar BV, Sundar S, Kunwar A, Prajapati VK (2017) Structure-based virtual screening, molecular docking, ADMET and molecular simulations to develop benzoxaborole analogs as potential inhibitor against Leishmania donovani trypanothione reductase. J Recept Signal Transduction 37(1):60-70

115. Lagarias P, Barkan K, Tzortzini E, Stampelou M, Vrontaki E, Ladds G, Kolocouris A (2019) Insights to the binding of a selective adenosine A3 receptor antagonist using molecular dynamic simulations, MM-PBSA and MM-GBSA free energy calculations, and mutagenesis. $J$ Chem Inf Model 59(12):5183-5197

116. Tang X, Wang Z, Lei T, Zhou W, Chang S, Li D (2018) Importance of protein flexibility on molecular recognition: modeling binding mechanisms of aminopyrazine inhibitors to Nek2. Phys Chem Chem Phys 20(8):5591-5605

117. Negron C, Pearlman DA, Del Angel G (2019) Predicting mutations deleterious to function in beta-lactamase TEM1 using MM-GBSA.Plos one, 14(3), e0214015

118. Paissoni C, Spiliotopoulos D, Musco G, Spitaleri A (2015) GMXPBSA 2.1: A GROMACS tool to perform MM/PBSA and computational alanine scanning. Comput Phys Commun 186:105-107

119. Salas-Burgos A, Iserovich P, Zuniga F, Vera JC, Fischbarg J (2004) Predicting the three-dimensional structure of the human facilitative glucose transporter glut1 by a novel evolutionary homology strategy: insights on the molecular mechanism of substrate migration, and binding sites for glucose and inhibitory molecules. Biophys J 87(5):2990-2999

120. Shukla R, Chetri PB, Sonkar A, Pakharukova MY, Mordvinov VA, Tripathi T (2018) Identification of novel natural inhibitors of Opisthorchis felineus cytochrome P450 using structure-based screening and molecular dynamic simulation. J Biomol Struct Dynamics 36(13):35413556

121. Verma P, Tiwari M, Tiwari V (2018) In silico high-throughput virtual screening and molecular dynamics simulation study to identify inhibitor for AdeABC efflux pump of Acinetobacter baumannii. J Biomol Struct Dynamics 36(5):1182-1194

122. Thirumal KD, Mendonca E, Priyadharshini CJ, George PDC, Zayed H (2019) A computational model to predict the structural and functional consequences of missense mutations in 06-methylguanine DNA methyltransferase. Advances in protein chemistry and structural biology, 115,351

123. Shukla R, Shukla H, Kalita P, Tripathi T (2018) Structural insights into natural compounds as inhibitors of Fasciola gigantica thioredoxin glutathione reductase. J Cell Biochem 119(4):3067-3080

124. Kubarenko A, Frank M, Weber ANR (2007) Structure-function relationships of Toll-like receptor domains through homology modelling and molecular dynamics. Biochem Soc Trans 35(6):1515-1518

125. Kumar DT, Mendonca E, Christy JP, Doss CGP, Zayed H (2019) A computational model to predict the structural and functional consequences of missense mutations in 06-methylguanine DNA methyltransferase. Adv Protein Chem Struct Biology 115:351-369

126. Baul HS, Rajiniraja M (2018) Mechanistic study of the inhibition of monoamine oxidase-B by quercetin as the potential therapeutic strategy for Parkinson's Disease: An in silico approach. J Comput Methods Sci Eng 18(4):1067-1073

127. Di Prinzio CL, Pereyra RG (2016) Molecular dynamics simulations of tilt grain boundaries in ice. Modell Simul Mater Sci Eng 24(4):045015

128. Shah M, Anwar MA, Yesudhas D, Krishnan J, Choi S (2016) A structural insight into the negative effects of opioids in analgesia by modulating the TLR4 signaling: An in silico approach. Sci Rep 6(1):1-15

129. Tian J, Wang P, Gao S, Chu X, Wu N, Fan Y (2010) Enhanced thermostability of methyl parathion hydrolase from Ochrobactrum sp. M231 by rational engineering of a glycine to proline mutation. FEBS J 277(23):4901-4908 
130. Joshi T, Sharma P, Joshi T, Chandra S (2020) In silico screening of anti-inflammatory compounds from Lichen by targeting cyclooxygenase-2. J Biomol Struct Dynamics 38(12):3544-3562

131. Torktaz I, Najafi A, Golmohamadi R, Hassani S (2018) Molecular dynamics simulation (MDS) analysis of Vibrio cholerae ToxT virulence factor complexed with docked potential inhibitors. Bioinformation 14(3):101

132. Raftopoulou S, Nicolaides NC, Papageorgiou L, Amfilochiou A, Zakinthinos SG, George P, Vlachakis D (2020) Structural Study of the DNA: Clock/Bmal1 Complex Provides Insights for the Role of Cortisol, hGR, and HPA Axis in Stress Management and Sleep Disorders. GeNeDis 2018. Springer, Cham, pp 59-71

133. Muthuvel SK, Elumalai E (2018) Molecular docking and dynamics studies of 4-anilino quinazolines for epidermal growth factor receptor tyrosine kinase to find potent inhibitor. J Recept Signal Transduction 38(5-6):475-483

134. Gajendrarao P, Krishnamoorthy N, Sakkiah S, Lazar P, Lee KW (2010) Molecular modeling study on orphan human protein CYP4A22 for identification of potential ligand binding site. J Mol Graph Model 28(6):524-532

135. Tanwar H, Kumar DT, Doss CGP, Zayed H (2019) Bioinformatics classification of mutations in patients with Mucopolysaccharidosis IIIA. Metab Brain Dis 34(6):1577-1594

136. Kumari R, Kumar R, Lynn A (2014) g_mmpbsa A GROMACS tool for high-throughput MM-PBSA calculations. Journal of chemical information and modeling, 54(7), 1951-1962

137. Paissoni C, Spiliotopoulos D, Musco G, Spitaleri A (2014) GMXPBSA 2.0: A GROMACS tool to perform MM/PBSA and computational alanine scanning. Comput Phys Commun 185(11):2920-2929

138. Wang E, Sun H, Wang J, Wang Z, Liu H, Zhang JZ, Hou T (2019) End-point binding free energy calculation with MM/PBSA and MM/GBSA: strategies and applications in drug design. Chem Rev 119(16):9478-9508

139. Kumar A, Srivastava G, Negi AS, Sharma A (2019) Docking, molecular dynamics, binding energy-MM-PBSA studies of naphthofuran derivatives to identify potential dual inhibitors against BACE-1 and GSK-3ß. J Biomol Struct Dynamics 37(2):275-290

140. Botelho FD, Dos Santos MC, Gonçalves ADS, Kuca K, Valis M, LaPlante SR, de Almeida JS (2020) Ligand-based virtual screening, molecular docking, molecular dynamics, and MM-PBSA calculations towards the identification of potential novel ricin inhibitors. Toxins 12(12):746

141. Elkarhat Z, Charoute H, Elkhattabi L, Barakat A, Rouba H (2020) Potential inhibitors of SARS-cov-2 RNA dependent RNA polymerase protein: molecular docking, molecular dynamics simulations and MM-PBSA analyses.Journal of Biomolecular Structure and Dynamics, $1-14$

142. Martins LC, Torres PHM, de Oliveira RB, Pascutti PG, Cino EA, Ferreira RS (2018) Investigation of the binding mode of a novel cruzain inhibitor by docking, molecular dynamics, ab initio and MM/PBSA calculations. J Comput Aided Mol Des 32(5):591-605

143. Kumari R, Lynn A (2011) Application of MM/PBSA in the prediction of relative binding free energy: Re-scoring of docking hit-list. J Nat Sci Biology Med 2(3):92-92

144. Shenai PM, Xu Z, Zhao Y (2012) Applications of principal component analysis (PCA) in materials science. Principal component analysis-engineering applications, pp 25-40

145. Chen J, Wang J, Zhu W (2016) Molecular mechanism and energy basis of conformational diversity of antibody SPE7 revealed by molecular dynamics simulation and principal component analysis. Sci Rep 6(1):1-12

146. Sittel F, Filk T, Stock G (2017) Principal component analysis on a torus: Theory and application to protein dynamics. J Chem Phys 147(24):244101

147. Riccardi L, Nguyen PH, Stock G (2009) Free-energy landscape of RNA hairpins constructed via dihedral angle principal component analysis. J Phys Chem B 113(52):16660-16668

148. Buslaev P, Mustafin K, Gushchin I (2020) Principal component analysis highlights the influence of temperature, curvature and cholesterol on conformational dynamics of lipids. Biochim et Biophys Acta (BBA)-Biomembranes 1862(7):183253

149. Nguyen PH (2006) Complexity of free energy landscapes of peptides revealed by nonlinear principal component analysis. Proteins Struct Funct Bioinform 65(4):898-913

150. Yamamoto N (2014) Hot spot of structural ambivalence in prion protein revealed by secondary structure principal component analysis. J Phys Chem B 118(33):9826-9833

151. Michielssens S, van Erp TS, Kutzner C, Ceulemans A, de Groot BL (2012) Molecular dynamics in principal component space. J Phys Chem B 116(29):8350-8354

152. Grasso G, Deriu MA, Tuszynski JA, Gallo D, Morbiducci U, Danani A (2016) Conformational fluctuations of the AXH monomer of Ataxin1. Proteins: Structure, Function, and Bioinformatics, 84(1), 52-59 
153. Verma S, Singh A, Kumari A, Tyagi C, Goyal S, Jamal S, Grover A (2017) Natural polyphenolic inhibitors against the antiapoptotic BCL-2. J Recept Signal Transduction 37(4):391-400

154. Mouritsen OG, Khandelia H (2012) Molecular mechanism of the allosteric enhancement of the umami taste sensation. FEBS J 279(17):3112-3120

155. Swain SS, Paidesetty SK, Dehury B, Sahoo J, Vedithi SC, Mahapatra N, Padhy RN (2018) Molecular docking and simulation study for synthesis of alternative dapsone derivative as a newer antileprosy drug in multidrug therapy. J Cell Biochem 119(12):9838-9852

156. Villa A, Stock G (2006) What NMR relaxation can tell us about the internal motion of an RNA hairpin: a molecular dynamics simulation study. J Chem Theory Comput 2(5):1228-1236

157. Ng HW, Laughton CA, Doughty SW (2013) Molecular dynamics simulations of the adenosine A2a receptor: structural stability, sampling, and convergence. J Chem Inf Model 53(5):1168-1178

158. Mukherjee S, Abdalla M, Yadav M, Madhavi M, Bhrdwaj A, Khandelwal R, Prajapati L, Panicker A, Chaudhary A, Albrakati A, Hussain T (2022) Structure-Based Virtual Screening, Molecular Docking, and Molecular Dynamics Simulation of VEGF inhibitors for the clinical treatment of Ovarian Cancer. J Mol Model 28(4):1-21

\section{Figures}

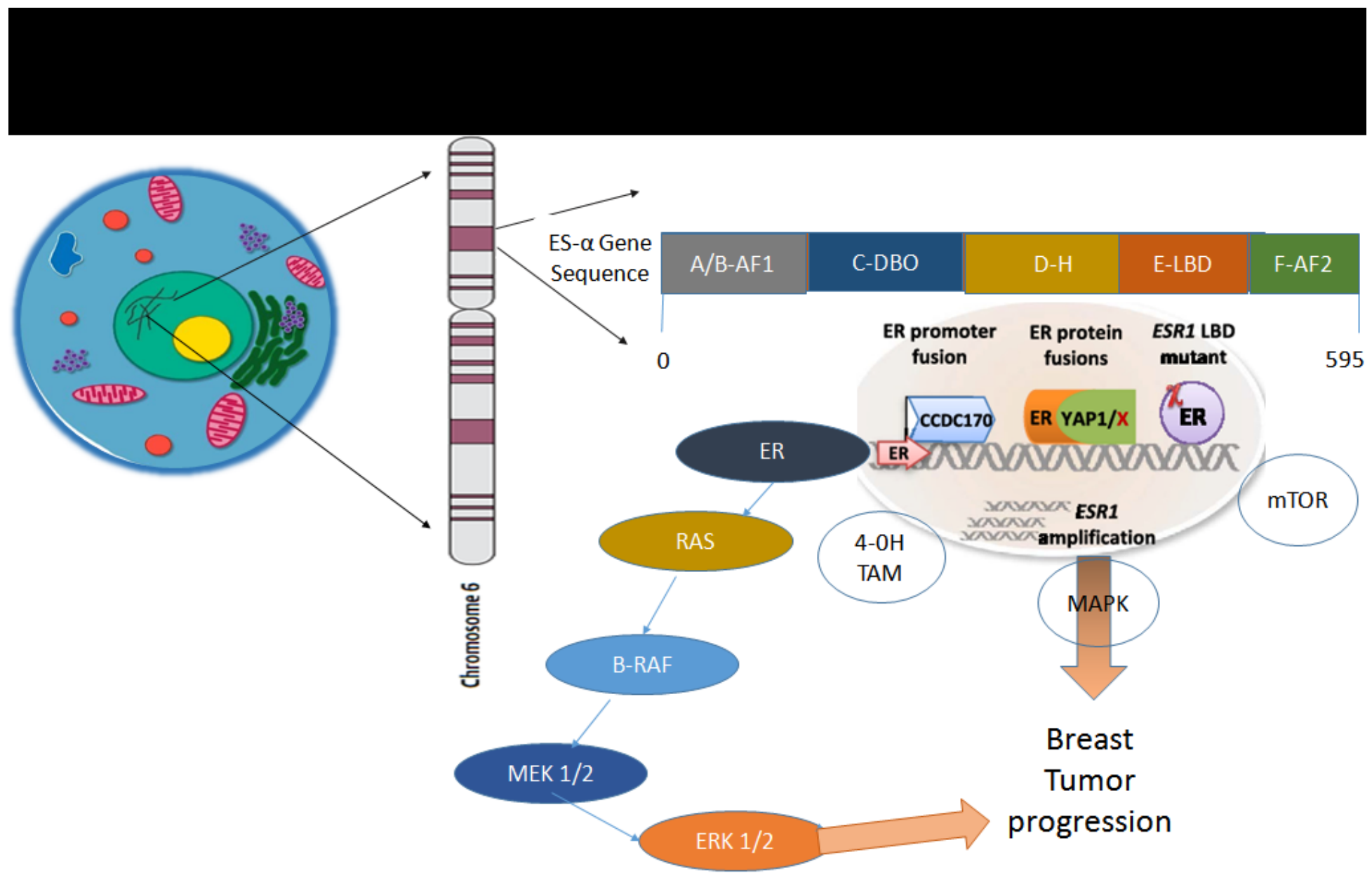

Figure 1

ESR1 interacting Pathway and Regulation of Breast Cancer Metastasis 


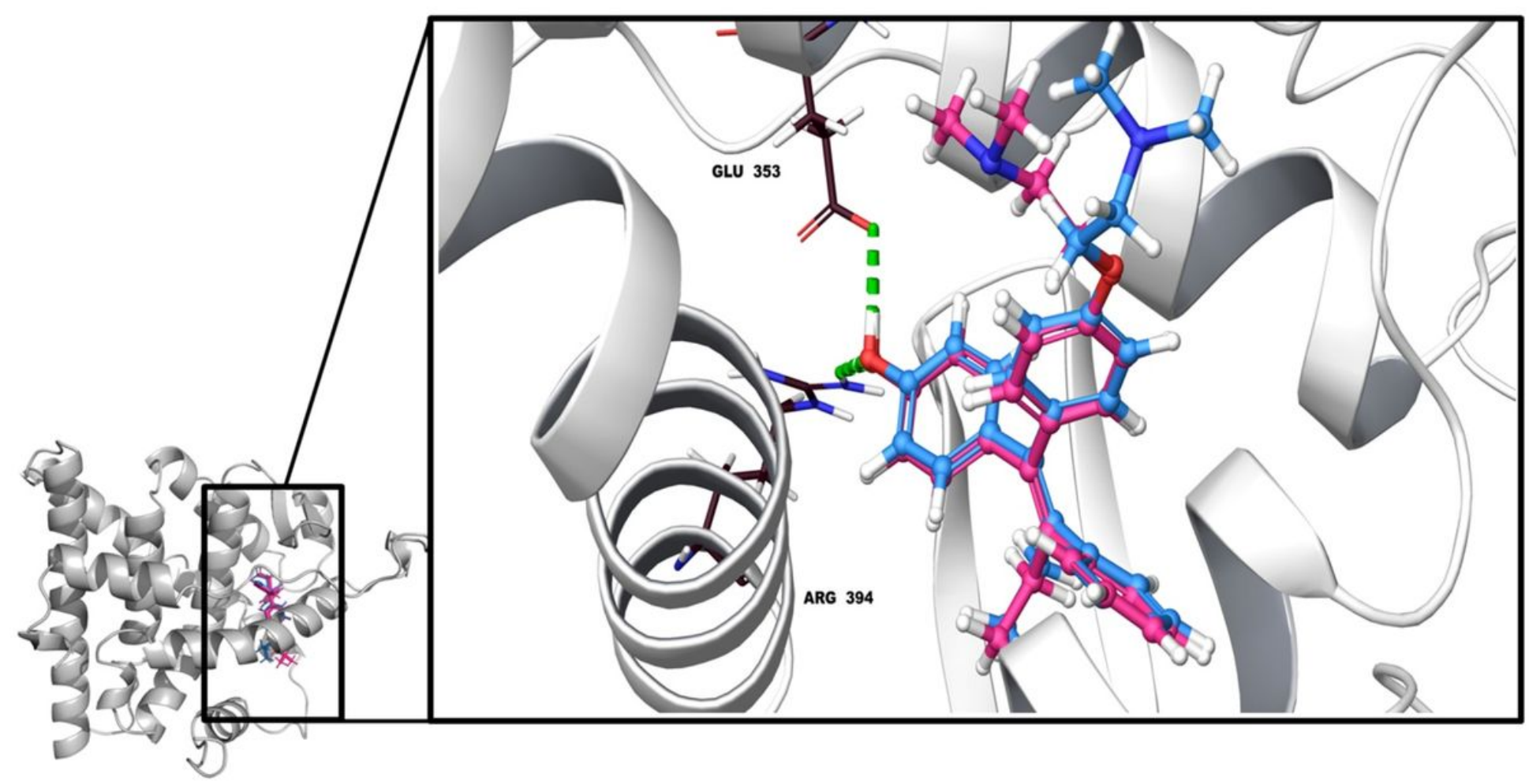

Figure 2

Superimposition of best-docked complex (blue) and known co-crystallized complex (pink) within the active site of ESR1.

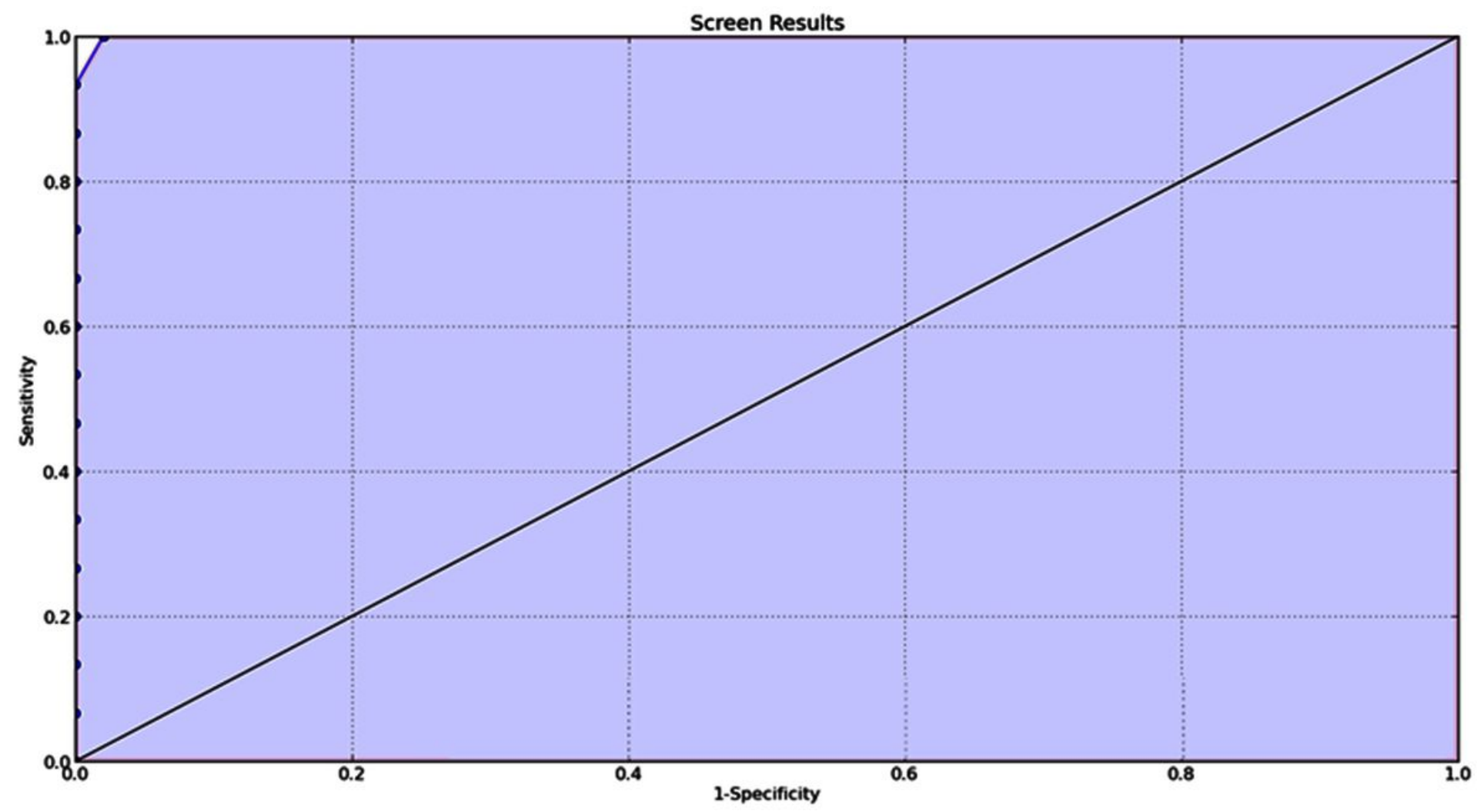

Figure 3

Graphical view of Enrichment curve for evaluating docking protocol for virtual screening. 

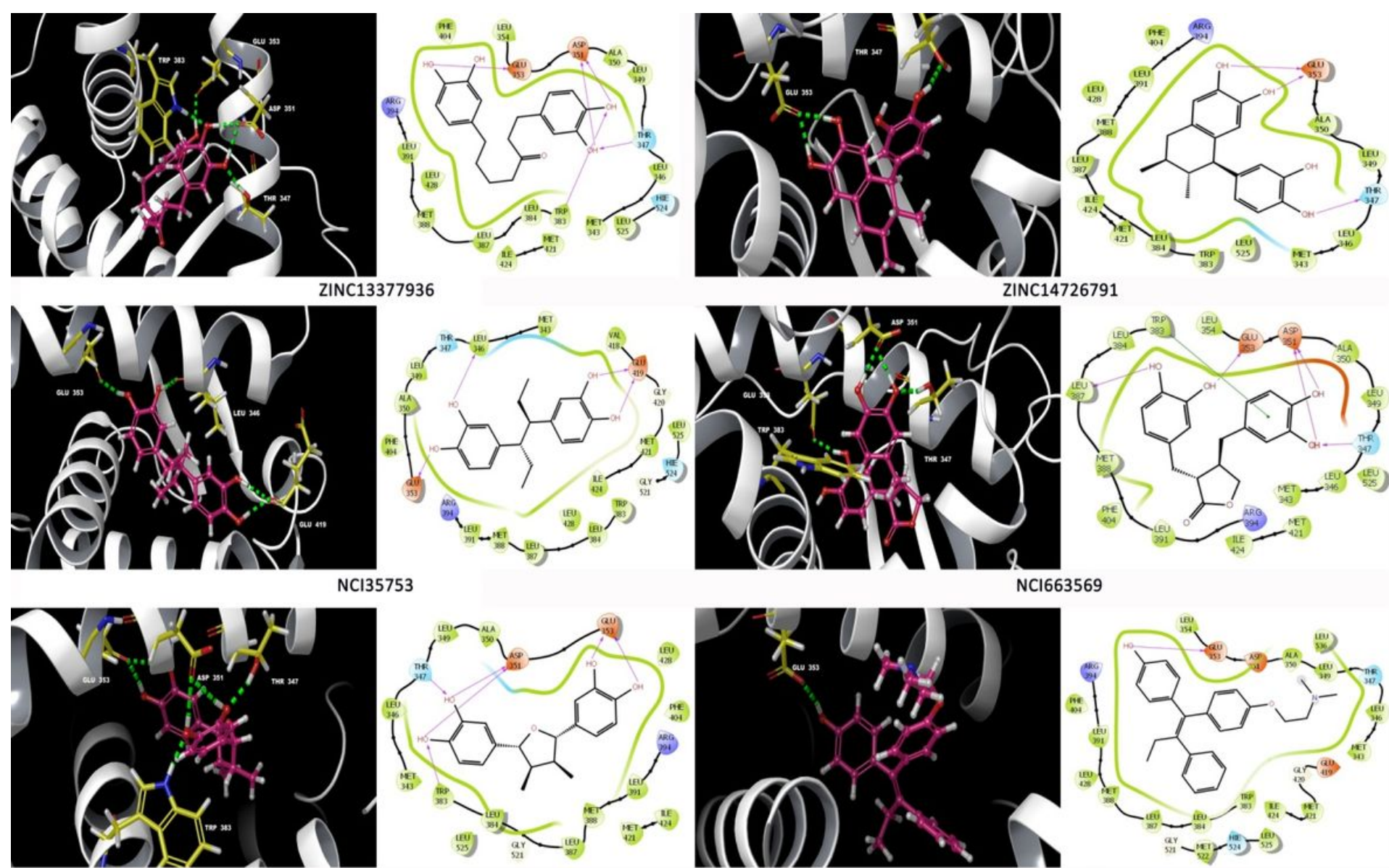

ZINC35465238

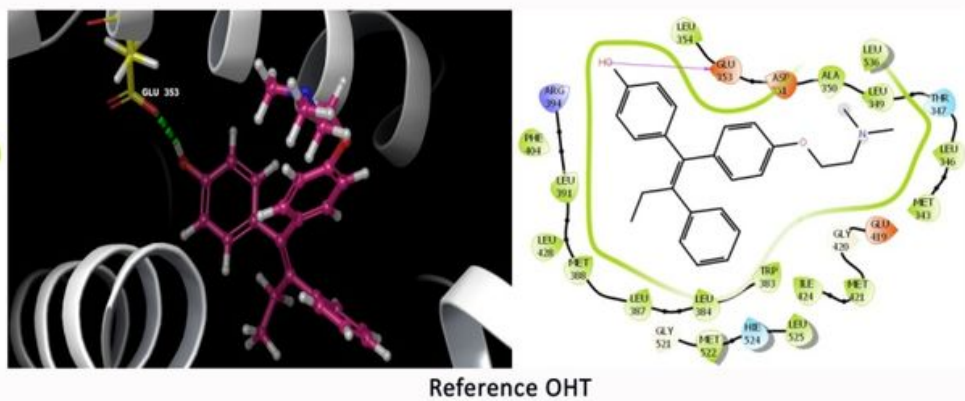

Figure 4

Closed3Dmolecularrepresentation 2D profile interaction analysis of protein-ligand complexes with, respectively. The hydrogen bonds are shown in green color dotted line. 


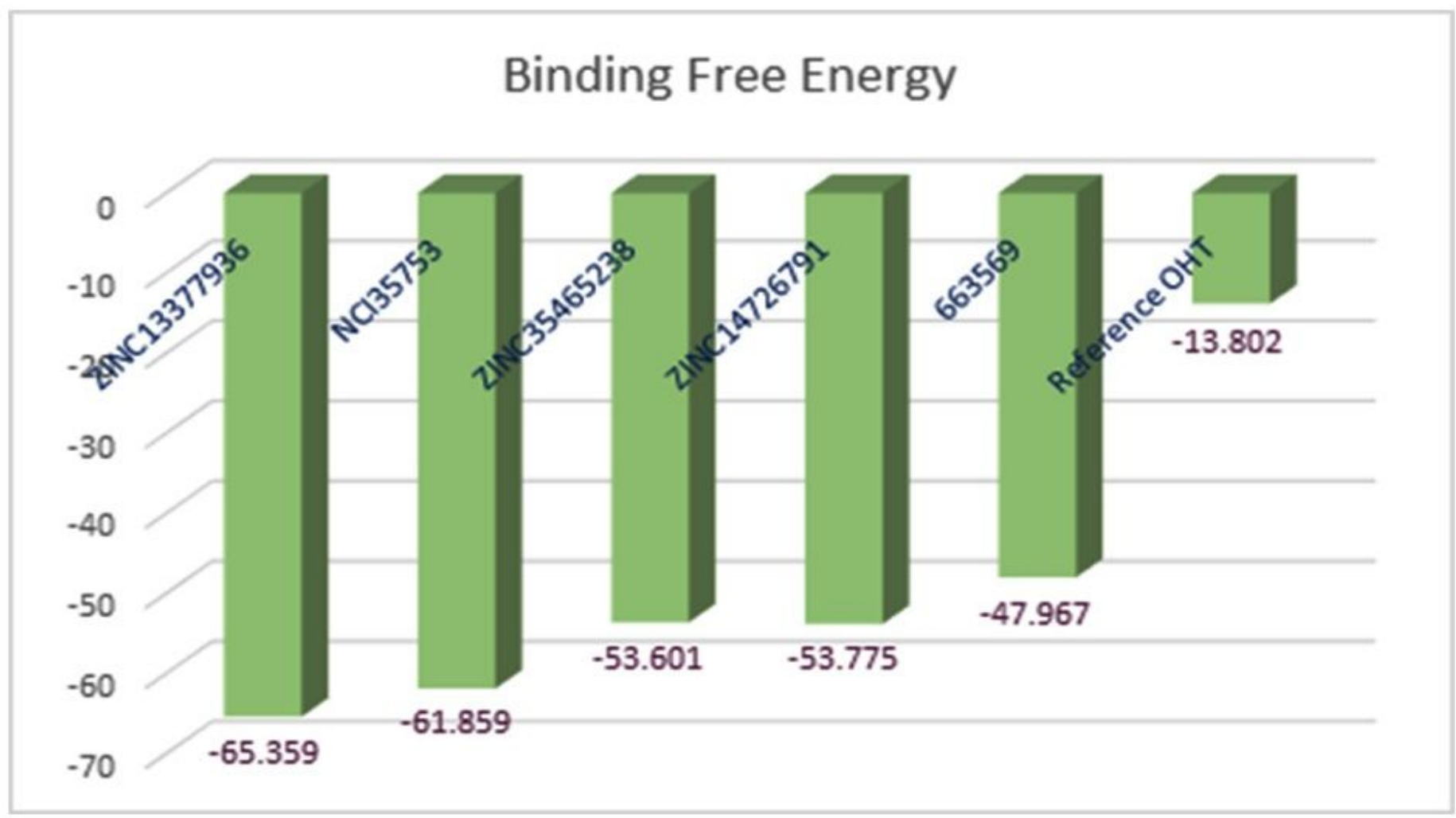

Figure 5

Graphical representation of binding free energy of all complexes. 

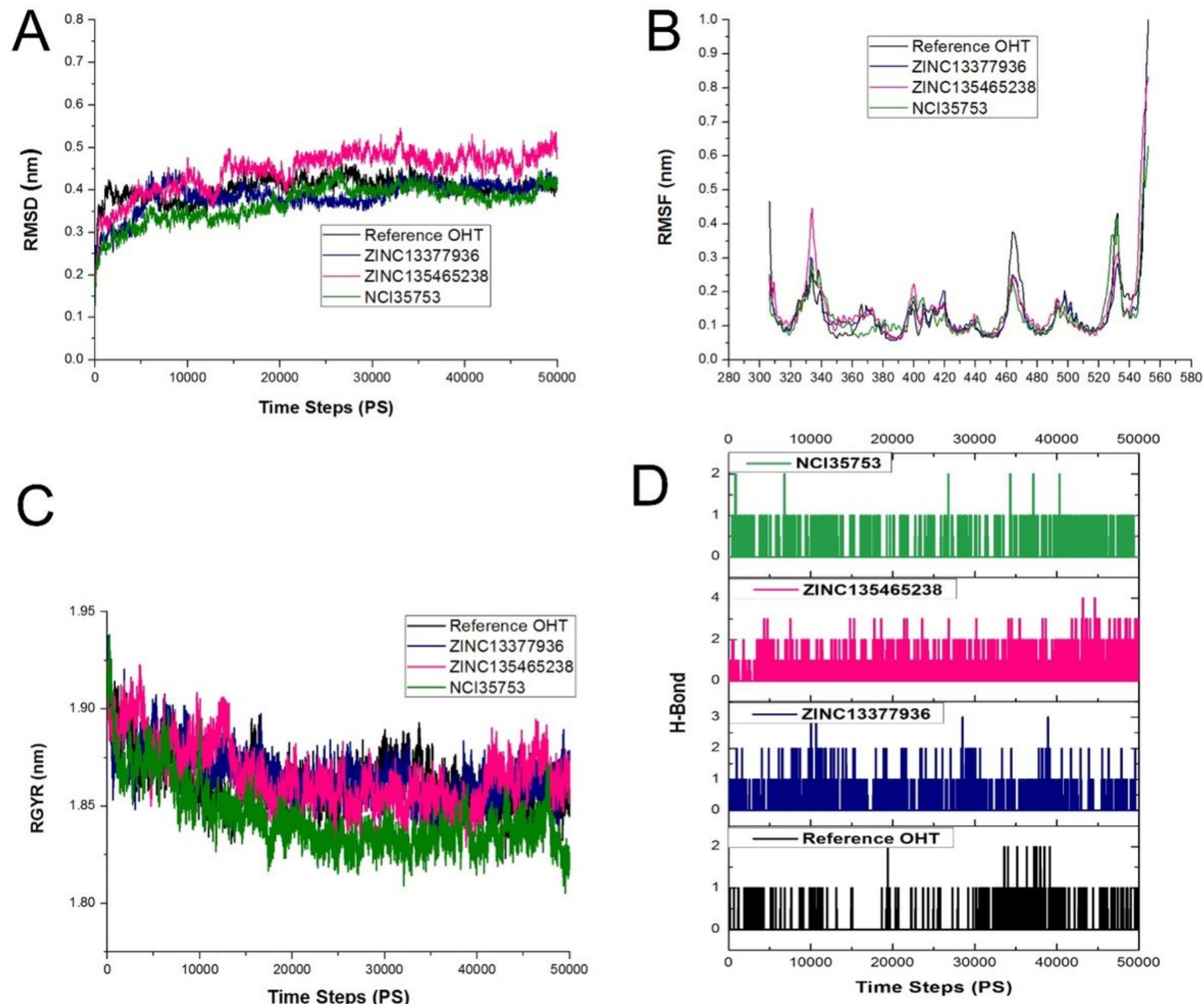

Figure 6

MDS profile of RMSD (A), RMSF (B), RGYR (C) and H-Bond interaction analysis (D). 


\section{$2 \mathrm{D}$ projection of trajectory}

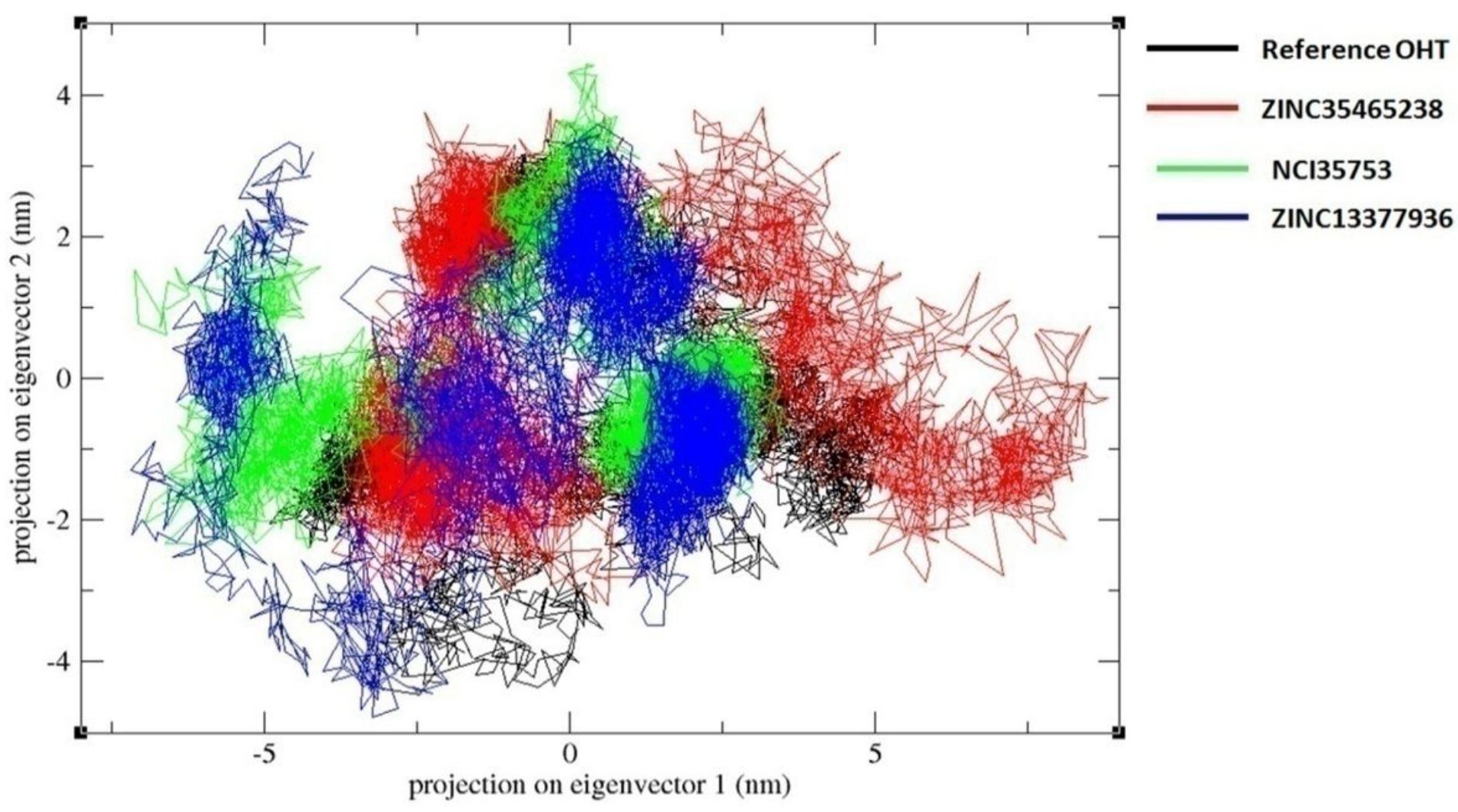

Figure 7

PCA plot constructed by eigenvector 1 vs. eigenvector 2 for the selected complexes. 


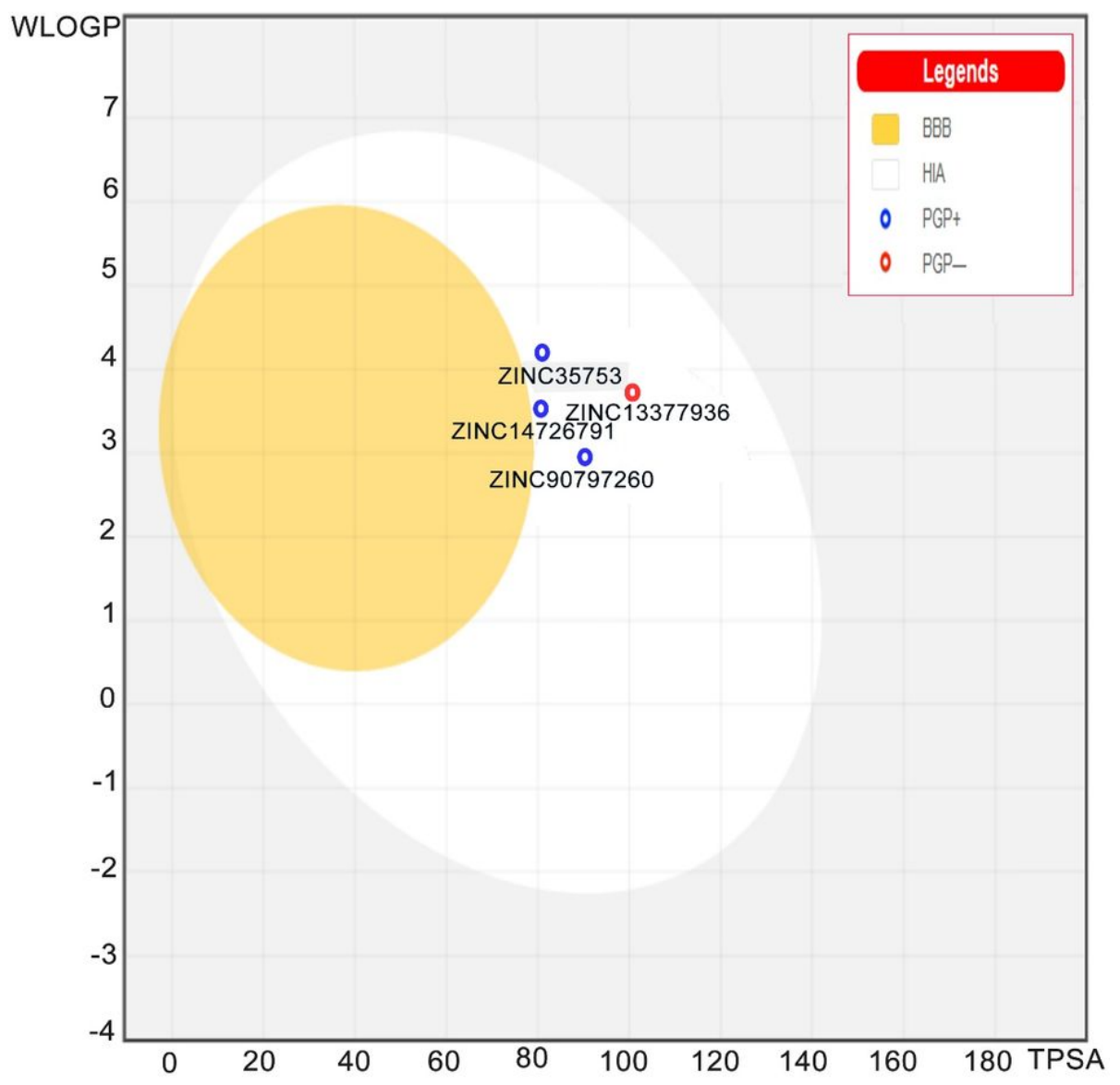

\section{Figure 8}

Boiled egg plot, water partition coefficient (WlogP) vs. Topological polar surface area (TPSA) of the hits Legends. 


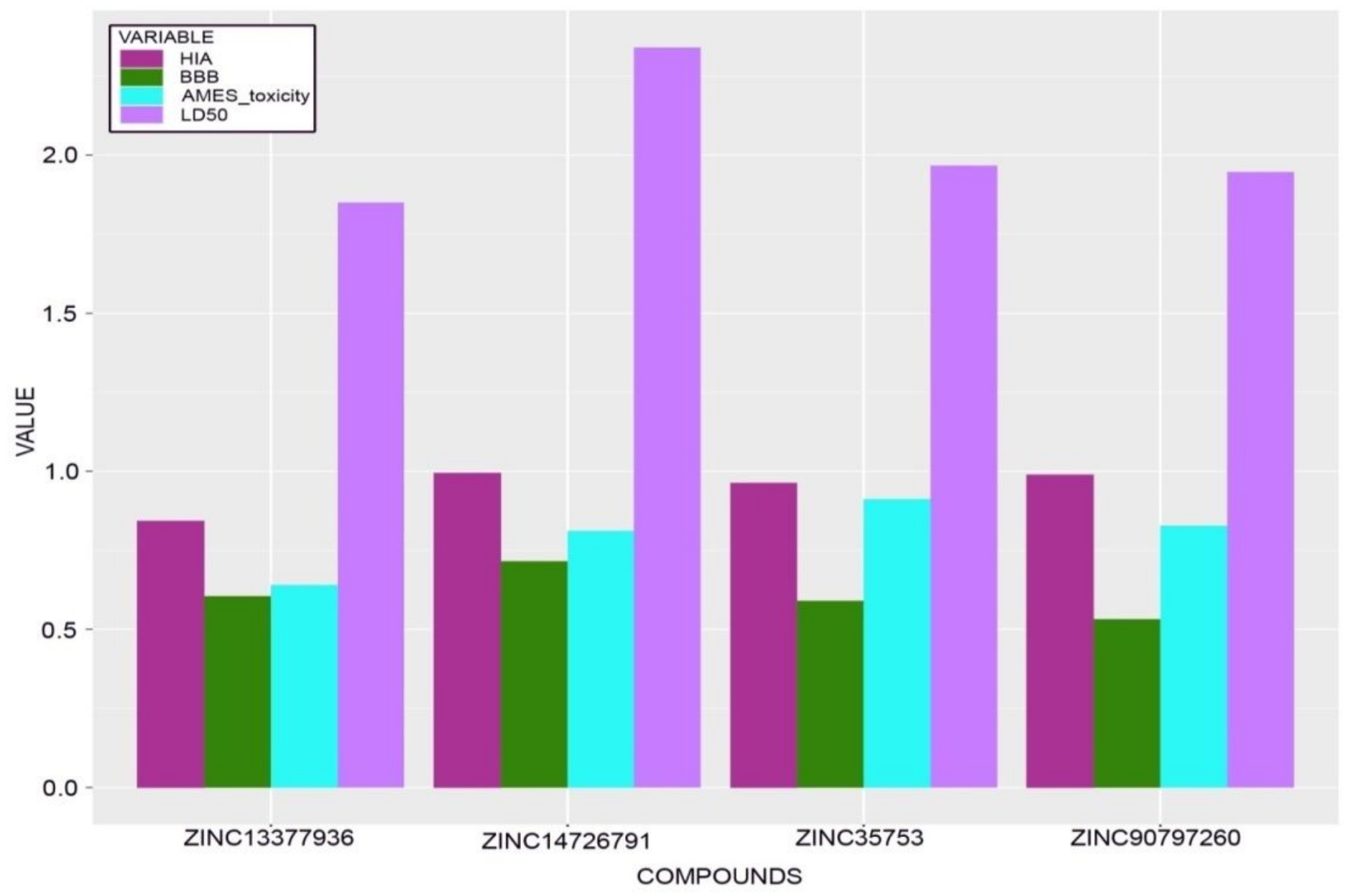

Figure 9

Comparative ADMET studies of BBB, HIA, AMES toxicityandLD50oftheestablishedandvirtualscreened compounds. 


\section{Collection of Biological target}

(PDB:3ERT)

2. Preparation of Protein and Ligands

3. Receptor Grid Generation and

Molecular Redocking

4. Virtual Screening, ADME and

Enrichment Calculation

5. Induced Fit Docking and MMGBSA calculation

6. MDS, MMPBSA and PCA studies

Figure 10

General workflow of the Current Study. 